\title{
VIII.
}

\section{Ueber die Einführung des provinzialen Kaisercultus im römischen Westen.}

Die vorliegende Untersuchung hat zum Zweck, die Zeit der Einrichtung des provinzialen Kaisercultus ${ }^{1}$ ) in den Provinzen des römischen Westens, vornehmlich im narbonensischen Gallien und in Baetica festzustellen und in Zusammenhang damit ein bisher unbeachtetes Princip nachzuweisen, wonach sich die ganze Einführungsgeschichte dieses Cultus richtete. Das Hauptgewicht wurde dabei auf die Frage über das Alter des narbonensischen Provinzialgesetzes gelegt, deren sicherere Entscheidung erst auf Grundlage einer detaillierten Untersuchung des erhaltenen Urkundenfragments möglich geworden ist. Diese anzustellen wäre mir unmöglich gewesen, wenn ich nicht einen Abklatsch der narbonensischen Bronzetafel zur Hand gehabt hätte, der mir durch eines Freundes Vermittlung von Herrn Professor Dr. Otto Hirschfeld mit großer Liebenswürdigkeit zur Benutzung überlassen wurde. Es ist mir eine angenehme Pflicht, dem genannten Gelehrten meinen Dank für diese wohlwollende Hülfe hiermit öfentlich auszusprechen.

I.

Das Datum der Einführung des provinzialen Kaisercultus in Gallia Narbonensis ist aus dem bekannten narbonensischen Gesetze C. XII 6038 zu entnehmen. Es ist, mit Rücksicht auf

1) Unter dem provinzialen Kaisercultus meinen wir, dem üblichen Sprachgebrauch folgend, den Kaisercult ganzer Provinzen, im Gegensatze zu demjenigen einzelner Municipien. 
die Geltung des Letzteren für die ganze Provinz sowie auf die Unabhängigkeit des provinzialen Kaisercultus vom municipalen, als feststehend anzusehen, daß dasselbe eine Ergänzung nicht des Stadtrechts von Narbo ${ }^{2}$ ), sondern der lex provinciae Narbonensis ist.

Die Meisten, die sich mit der Altersbestimmung des obigen Documents beschäftigt haben, schreiben es der Zeit des Augustus zu, indem sie in Z. 27 imaginesve imperatoris Caes[aris Augusti] und in Z. 13 imperator [Caesar Augustus] lesen ${ }^{3}$ ).

Diese Ansicht ist bis jetzt außer mir ${ }^{4}$ ) nur von Mispoulet bestritten worden, der das fragliche Gesetz als der Regierungszeit eines der nächsten Nachfolger des Augustus angehörig betrachtet ${ }^{5}$ ). Von den beiden Grïnden, mit welchen dieser Gelehrte seine Meinung anfangs zu stützen suchte, will ich mich nur mit Einem beschäftigen, weil Mispoulet selbst auf den anderen später verzichtet zu haben scheint ${ }^{6}$ ). Er weist nämlich auf die vielbesprochene Stelle der taciteischen Annalen $(1,78)$ zum J. $15 \mathrm{n}$. Chr. hin: templum ut in colonia Tarraconensi strueretur Augusto petentibus Hispanis permissum datumque in omnes provincias exemplum, und meint, daß die von 'Tacitus berichtete Thatsache als das erste Beispiel der officiell erlaubten Consecration eines dem provinzialen Kaisercultus gewidmeten Tempels, somit als das erste Beispiel der officiellen Einrichtung dieses Cultus überhaupt zu betrachten sei, wodurch die Möglichkeit der Annahme, daB Augustus selbst der Urheber eines solchen in irgend einer anderen Provinz (also speciell in Gallia Narbo-

2) Die in ZZ.17 u. 18 des Gesetzes vorkommenden Worte si flamen in civitate esse desierit, auf welche sich die entgegengesetzte Heinung stützt (Bruns Fontes ${ }^{6}$ I p. 140 sq.), sind zuerst von O. Hirschfeld richtig erklärt worden in der Zeitschr. für Rechtsgesch., Roman. Abth., 188 S. $403 \mathrm{f}$.; vgl. auch Alibrandi Bullettino dell' Istituto di diritto romano I. Bd. (Heft $4-5$, Roma 1889) S. 183 f. und Mispoulet Bullet. crit. 1890 S. 7 sowie 1888 S. $254 \mathrm{f}$.

3) Mommsen Staatsrecht III 2 S. VII Anm. 1 (vgl. Bruns 1. 1.); Hirschfeld C. XII p. $864 \mathrm{sq}$, und Sitzungsber. der Berliner Akademie 1888 S. 848 ; Alibrandi a. a. O. S. 174; Beurlier Le culte imperial, son histoire et son organisation depuis Auguste jusqu'a .Justinien (Paris 1891) S. 21. Dieselbe Ergänzung wird auch von Mispoulet beibehalten, von dessen Meinung unten die Rede sein wird.

*) In meiner russisch geschriebenen Dissertation über „die römischen Municipalpriester" (St. Petersburg 1891) S. 65-67" Anm. 52. Meine darin kurz entwickelte Ansicht über das Alter des narbonensischen Gesetzes wird in diesem Aufsatz ausführlicher begründet.

5) Bulletin critique 1888 S. 187. 196. $256 \mathrm{f.,}$ vgl. ebendas. 1890 $\mathrm{S}, 11$. $\mathrm{Zu}$ vergleichen ist auch Brissaud in der französischen Bearbeitung des Mommsen-Marquardt'schen Handbuchs Bd. XIII (Paris 1890) S. 403.

6) Bull. crit. 1890 S. 11. Zur Widerlegung dieses Arguments vgl. Hirschfeld Sitzungsber. S. $850 \mathrm{f}$. und Beurlier S. 23.

Brought to you by | Université Paris Ouest Nanterre La Défense 
nensis) gewesen sei, natürlich ausgeschlossen wird. Es habe, meint Mispoulet, auch vor dem J. 15 einige dem Augustus gewidmete Altäre gegeben, wie die ara Lugdunensis und die von Tacitus selbst erwähnte ${ }^{7}$ ) ara Ubiorum; wenn nun dieser Geschichtsschreiber trotzdem sage, daß das erste Beispiel einer dem Zwecke des Provinzialcultus dienenden Tempelgründung von Hispania Tarraconensis gegeben worden sei, so habe er dazu gewiß einen guten Grund. Das einfachste Mittel, diesen scheinbaren Widerspruch aufzuheben, sei die Annahme, daß die erste officielle Consecrierung eines Provinzialtempels im tarraconensischen Spanien stattgefunden habe, während die Tempel anderer Provinzen die officielle Anerkennung noch nicht gefunden hätten. Wäre das concilium des narbonensischen Galliens von Augustus selbst eingerichtet worden, so würde die Behauptung des Tacitus, dem ja, als Agricola's Schwiegersohn, Galliens Verhältnisse wohl bekannt gewesen sein müssen, ganz unerklärlich sein ${ }^{8}$ ).

Hiergegen führt Beurlier mit Recht die sicher officiell genehmigte Einweihung des pergamenischen Tempels an, die dem Tacitus bei Abfassung der fraglichen Stelle wohl nicht entgangen sein konnte ${ }^{9}$ ): will also Mispoulet seine Annahme aufrecht erhalten, so muß er dieselbe natürlich auf die occidentalischen Provinzen beschrünken; doch würde die Voraussetzung einer solchen Entgegenstellung der orientalischen und occidentalischen Provinzen wohl ganz willkürlich sein ${ }^{10}$ ).

Der weiteren Annahme von Mispoulet aber, welche aus seiner Erklärung der taciteischen Stelle nothwendig folgt, nämlich daß allen übrigen, aus der Zeit vor dem J. $15 \mathrm{n}$. Chr. nachweisbaren Consecrierungen der Provinzialtempel bzw. Altäre (im Westen), wie der des Lyoner Altars oder der ara Ubiorum, der officielle Charakter ganz abgeht, läßt sich die Thatsache entgegensetzen, daB alle auf die Einführung des Kaisercultus in einzelnen Provinzen bezüglichen positiven Nachrichten für die Zeit sowohl vor als nach dem J. 15 n. Chr. gerade das Gegentheil bezeugen ${ }^{11}$ ). Ja man kann auf Grund dieser Nachrichten die

7) Ann. 1, 39. 57.

8) Bull. crit. 1888 S. 256, vgl. ebendas, 1890 S. 11.

9) Er selbst erwähnt diese Thatsache, Ann. 4, 37: cum divus Augustus sibi atque urbi Romae templum apud Pergamum sisti non prohibuisset.

10) Beurlier S. 22.

11) So wird der Provinzialcultus im narbonensischen Gallien durch eine kaiserliche lex data eingeführt. Die Kaisertempel der Provinz Asien zu Pergamon und Fphesos, sowie die bithynischen Provinzialtempel zu Nikomerlia und Nikaea sind mit Genehmigung des Augustus, der Lyoner Altar unter persönlicher Mitwirkung des Drusus gegründet worden (Tac. Ann. 4, 37. Dio Cass. 51, 20,6 sq. 54, 32, 1). Fbenfalls haben das tarraconensische Spanien im J. 15, die Provinz Asion im

J. 23, Baetica im J. 25 an Tiberius ihre Gesuche um die Einrichtung 
principielle Behauptung aufstellen, daß die Einrichtung des Provinzialcultus immer ein Staatsact sein mußte.

Andererseits ist auch die Erklärung von Beurlier nicht besser gelungen. Er bezieht nämlich willkürlicher Weise die Worte omnes provincias nur auf die ïbrigen spanischen Provinzen, d. h. auf Baetica und Lusitanien 1z), - doch würde Tacitus, um den ihm von Beurlier zugemutheten Gedanken auszudrücken, anstatt in omnes provincias zu sagen gewiß sich irgend einer anderen Redensart bedient und auch im vorhergehenden Satz schwerlich schlechterdings Hispanis gesagt haben.

Es bleibt also nichts übrig als die Worte omnes provincias auf alle Provinzen des römischen Reichs zu beziehen, was durch eine nähere Untersuchung des Thatbestandes vollkommen bestätigt wird. Es sagt nämlich Sueton Aug. 52: templa quamvis sciret etiam proconsulibus decerni solere, in nulla tamen provincia nisi communi suo Romaeque nomine recepit, und in der That ist kein Tempel auf dem römischen Provinzialboden nachzuweisen, der bei Lebzeiten des Augustus zu Ehren desselben allein errichtet worden wäre ${ }^{13}$ ): abgesehen von den der Göttin Roma und dem divus Iulius gewidmeten 'Tempeln zu Ephesos und Nikaea ${ }^{14}$ ) waren alle uns bekannten Kaisertempel jener Epoche, wie die in Pergamon und Nikomedia ${ }^{15}$ ), Ankyra ${ }^{16}$ ), Mylasa ${ }^{17}$ ), Athen ${ }^{18}$ ),

bzw. Erweiterung des Kaisercultus gerichtet (Tac. Ann. 1, 78. 4, 15.37), und die Ablehnung des baetischen Gesuchs, in Folge deren der Kaisercultus in dieser Provinz damals nicht eingeführt werden konnte, macht es unzweifelhaft, daß eine kaiserliche Erlaubniß keine leere Formalität, sondern die nothwendige Bedingung für die Cultuseinrichtung war.

${ }^{12}$ ) Le culte impérial S. 22.

18) Mit diesen in den Provinzen befindlichen Kaisertempeln sind natürlich diejenigen nicht zu verwechseln, die von einigen Vasallkönigen in ihren Reichen, also außerhalb des eigentlichen Provinzialgebiets, zu Ehren des Augustus allein bei Lebzeiten desselben erbaut worden sind, wie in Mauretanien unter Juba's Regierung (L. Müller, Numism. de l'anc. Afrique III S. 105 n. 55, vgl. auch S. 106 n. 56). Wohl mögen auch die von Herodes in Samaria-Sebaste (Joseph. B. Iud. $1,21,2)$ und bei Caesarea Philippi (Antiq. 15, 10, 3) errichteten vaoi Katoapos dem Augustus allein geweiht gewesen sein; doch war der von demselben König zu Caesarea Palaestinae gegründete Tempel sicherlich dem gemeinschaftlichen Roma- und Augustuscultus gewidmet ( $B$. I $u d$.

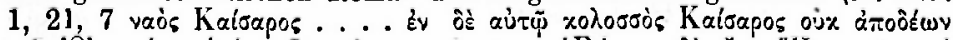

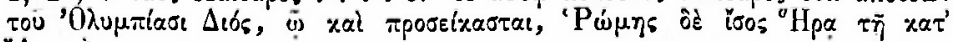
"Apros).

14) Dio Cass. 51, 20, 6 (s. unten Anm, 20).

15) Dio Cass. 51, 20, 7; Tac. Ann. 4, 37.

16) C. I. G. $4039=$ Perrot Expl. arch. de la Galatie et de la

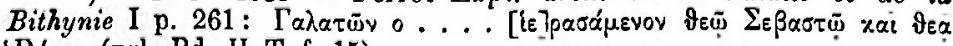

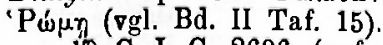

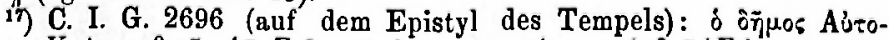

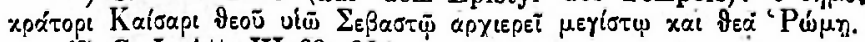

${ }^{18}$ C. I. Att. III 63.334 .

Broüght to you by 63 Université Paris Ouest Nanterre La Défense 
Lugdunum ${ }^{19}$ ), dem Augustus in Gemeinschaft mit der genannten Göttin geweiht. Freilich sind Autoren ${ }^{20}$ ), ja manchmal auch Inschriften ${ }^{21}$ ), in der Angabe dieser Dedicationen nicht immer correct genug; man wird aber den Grund solcher Ungenauigkeiten verstehen, wenn man sich daran erinnert, daß die Anknüpfung des Romacultus an den des Augustus fast eine reine Formalität war, wenngleich diese von Augustus selbst stets verlangt wurde.

So wird es ersichtlich, daß Tacitus von einem datum in omnes provincias exemplum deshalb spricht, weil das tarraconensische Spanien die erste Provinz war, welche einen Tempel zu Ehren des Augustus allein errichtete ${ }^{22}$ ). Ist aber dem so, so fällt der Hauptgrund weg, aus welchem Mispoulet die Erlassung des narbonensischen Gesetzes einem der nächsten Nachfolger des Augustus zuschreibt.

19) Der lugdunensische Tempel scheint schon bei Strabo 4, 3, 2 erwähnt zu sein (vgl. Hirschfeld Sitzungsber. S. 839 Anm. 30 u. S. 840

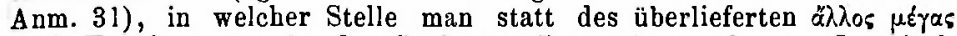

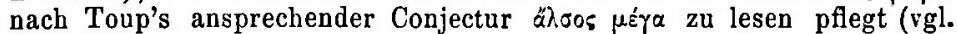
dazu Müller Numism. de l'anc. Afr. III S. 122 Anm. 8). Ich möchte jedoch statt $\ddot{a} \lambda \lambda_{0 s}$ lieber vaós schreiben, vgl. z. B. Boissieu p. 84 sacerdoti ad templ[um] Rom(ae) et Aug(usti) ad confluent(es) Avaris et Rhodani; p. 114 sa[cerdoti] ad aram Caes. n(ostri) [apud te m] plum Romae et [Augusti in]ter confluen[tes Araris] et Rhoda[ni]. Freilich erblickt Büchner (Philol. 1891 S. 758 nebst Anm. 27) in diesem templum bloß den heiligen Bezirk mit Rücksicht darauf, daß Autoren und Münzen des Altars allein Erwähnung thun, doch halten wir seine Erklärung für gezwungen. Die Dürftigkeit der auf den Tempel bezüglichen Nachrichten aber könnte schlechterdings dadurch erklärt werden, daß der vor der Beendigung des Tempelbaus provisorisch errichtete Altar derweilen zur ältesten und eigentlichen Cultusstätte geworden war, weshalb der Tempel selbst neben ihm im Hintergrunde blieb (es ist $\mathrm{zu}$ beachten, daß alle datierbaren Inschriften, in denen das lugdunensische templum erwähnt wird, dem zweiten Jahrhundert angehören).

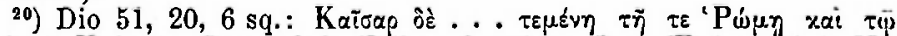

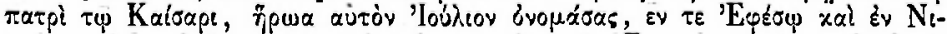

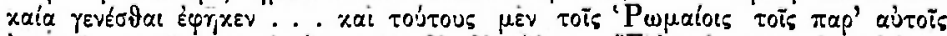

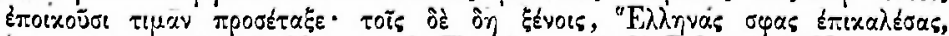

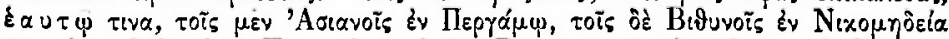

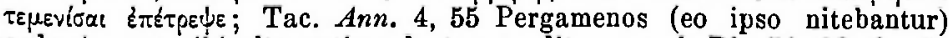
aede Augusto ibi sita satis adeptos creditum; vgl. Dio 54, 32, 1 iñs

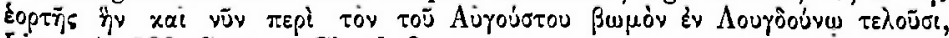
Liv. epit. 139, Sueton. Claud. 2.

$\left.{ }^{21}\right)$ Doch nur griechische, wie z. B. das zu Ehren des Augustus

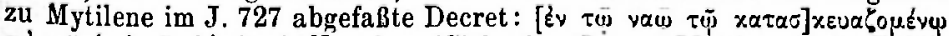

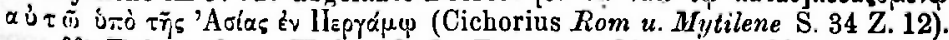

22) Vgl. noch $v$. Hadr. 12, 3 Tarracone hicmarit, ubi sumptu suo aedem Augusti restituit, und $v$. Severi 3, 4 somniavit primo sibi dici, ut templum Tarraconense Augusti, guod iam labebatur, restitueret. Die Mögli chkeit der obigen Erklärüng ist schon von Nipperdey z. St. beiläufig anggl|entet ou by | Université Paris Ouest Nanterre La Défense 
Indem wir uns nun der Prüfung der herrschenden Meinung über das Alter des obigen Documents zuwenden, wollen wir, bevor wir auf die Beweise unserer Gegner eingehen, zunächst einige Umstände hervorheben, die der üblichen Zeitbestimmung zuwiderlaufen.

\section{II.}

Einen Aufsclluß über die Abfassungszeit des narbonensischen Gesetzes, und zwar zu Ungunsten der herrsclienden Meinung, giebt uns die folgende athenische Inschrift, C. I. Att. III

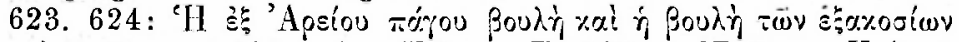

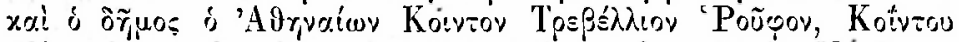

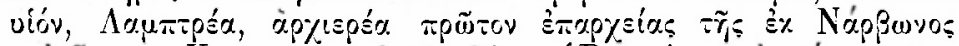

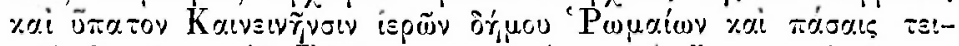

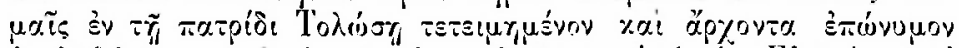
Èv 'A

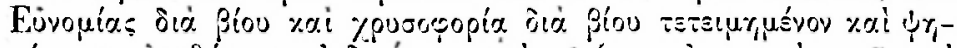

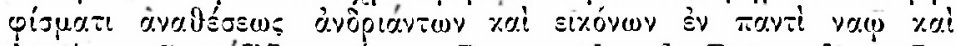

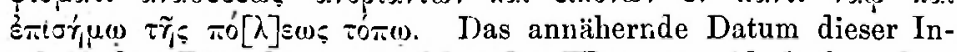
schrift hat Dittenberger in folgender Weise unwiderlegbar festgestellt: 'ad alterum p. Chr. saeculum titulum pertinere cum prolixa honorum enumeratio tum iota productum constanter per diphthongum EI scriptum prodit. Quum igitur post annum 126 p. Chr. propter sexcentorum senatum titulus compositus esse nequeat, sub finem imperii Traiani aut initio Hadriani erectus esse videtur' ${ }^{23}$ ).

Es lebte also noch in den letzten Regierungsjahren Trajans oder zu Anfang der Regierung Hadrians der der Zeit nach erste Provinzialpriester des narbonensischen Galliens. Es erhebt sich freilich gegen diese von den Meisten ${ }^{24}$ ) angenommene Erklärung

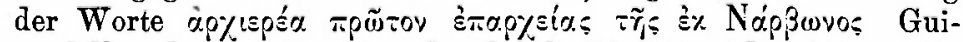
raud ${ }^{25}$ ), der meint: 'rien de plus legitime que de separer jo-

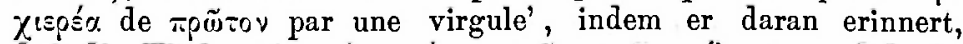

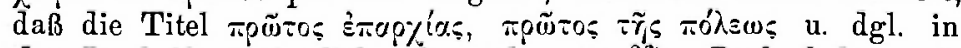
den Inschriften ziemlich oft vorkommen ${ }^{26}$ ). Doch haben wir

${ }^{23}$ ) Irrig hat Marquardt die fragliche Inschrift der Zeit des Tiberius zugeschrieben (Eph. epigr. I p. 203). DaB diese Meinung schon von Dittenberger widerlegt worden ist, scheint Mispoulet unbekannt geblieben zu sein (vgl. unten Cap. XVI).

24) Vgl. z. B. Dittenberger C. I. Att. III ind. p. 340, Wilmanns de sacerd. p. p. R. quod. genere (Berol. 1867) p. 42, Herzog Gall. Narbon. p. 255, Marquardt l. 1.

$\left.{ }^{25}\right)$ Les assembl. provinciales dans l'Empire romain, Paris 1887 p. 83 , auch in den Comptes rendus de l'Acad. des sciences mor. et polit. N. S. XXX (1888) p. 263 sq. Ihm folgt Beurlier p. $121 \mathrm{sq.}$

${ }^{26}$ ) Doch ist das einzige von ihm (Les assembl. prov. S. $83 \mathrm{Anm} .3$ ) aus lateinischen Inschriften angeführte Beispiel eincs solchen Titels 
dagegen Folgendes zu erwidern: erstens, sind die sämmtlichen Namen der dem Q. Trebellius Rufus zu Theil gewordenen Auszeichnungen in seiner Inschrift durch die Partikel xai mit einander verbunden: wäre also die von Guiraud gegebene Erklärung richtig, so würde dieselbe Partikel auch da stehen, wo er das Komma setzen will. Es würde, zweitens, der Mangel an einer Ortsbestimmung beim Titel $\partial \rho / \imath \rho £ \alpha$ sehr auffallend sein, zumal da solche Ortsangaben bei den übrigen Titeln des Rufus durchaus nicht fehlen ${ }^{27}$ ). Man ziehe endlich in Betracht, daß

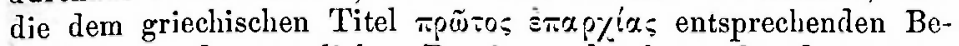
zeichnungen den westlichen Provinzen durchaus fremd gewesen zu sein scheinen; wenigstens ist bis jetzt noch kein sicheres Beispiel einer solchen Ehrenbenennung aus diesen Provinzen bekannt geworden ${ }^{28}$ ).

Die obigen Gründe veranlassen uns die Guiraud'sche Erklärung abzuweisen und an der Auffassung des Wortes mpö̃zov im chronologischen Sinne festzuhalten, zumal da alle sonst ver-

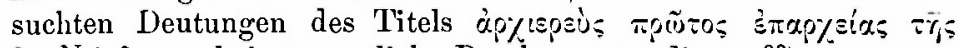
غ̇ Náp $\beta \omega v 0 s$ keine ernstliche Beachtung verdienen ${ }^{29}$ ).

Ist nun die iibliche Zeitbestimmung des narbonensischen Gesetzes richtig, so muß Rufus als der erste Provinzialpriester von Gallia Narbonensis dieses Priesterthum spätestens im J. 14 n. Chr., ja wahrscheinlich noch einige Jahre früher ${ }^{30}$ ) bekleidet haben. Diese Würde aber erreichte man in der Regel erst, nachdem man den municipalen cursus honorum abgeschlossen hatte, d. h. nicht vor dem 30. Lebensjahre ${ }^{31}$ ). l'reilich konnten

nicht treffend gewählt, denn es wird in C. III 1051 nicht "primus munipit" erwähnt, wie es Guiraud citiert, sondern patron(us) col(legii) fabr(um) prim(us) mun(icipii) Sept(imii) Apulli), vgl. Mommsen C. III p. 183.

$\left.{ }^{27}\right)$ Uebrigens scheint auch Guiraud selbst diese Schwierigkeit gefühlt zu haben, vgl. Les assembl. prov. p. 83: 'il resultera neme de cette ponctuation un léger doute sur la nature du sacerdoce exerce par Rufus' u. s. w.

${ }^{28}$ ) „Peut-etre aussi faudrait-il une virgule apres Augustalis", sagt Guiraud"Les assembl. prov. S. 83 Anm. 4 betreffs C. II 3271 flamini Augustali in Baetica primo, doch ist diese Erklärung entschieden abzuweisen, vgl. unten Cap. XIII.

$\left.{ }^{29}\right)$ Wir meinen den Erklärungsversuch von Lebegue im Bullet. epigr. IV (1884) p. 72 (vgl. auch Herzog Gall. Narb. p. 256) und die ebendas. mitgetheilte Vermuthung Allmer's. - I)as Wort rewirov auf' den Rang des Priesters zu beriehen ist deshalb unmöglich, weil es feststeht, daß nur je Ein Provinzialpriester in jeder Provinz alljährlich gewählt wurde.

$\left.{ }^{30}\right)$ Vgl. Hirschfeld Sitzungsber. S. 840 Anm. 33.

31) Vgl. Hirschfeld 1. 1. S. 851 f., Guiraud Les assembl. prov. p. 85. Was aber speciell Rufus anbetrifft, so sagt die athenische Inschrift

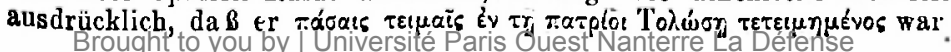


dabei auch Ausnahmen vorkommen ${ }^{32}$ ), doch sind keine solchen aus der früheren Kaiserzeit nachzuweisen. Wenn wir ferner die athenische Inschrift durchschnittlich an das Jahr $117 \mathrm{n}$. Chr., d. h. an Trajans Todesjahr anknüpfen, so müssen wir - unter der obigen Voraussetzung - uns die Annahme gefallen lassen, daß Rufus zur Zeit der Abfassung seiner athenischen Inschrift etwa 133 Jahre alt war, was jedenfalls sehr bedenklich ist. Ohne Zweifel hat eben diese Erwägung Lebègue ${ }^{39}$ ) und nachher Guiraud ${ }^{34}$ ) bewogen, die chronologische Deutung des Wortes

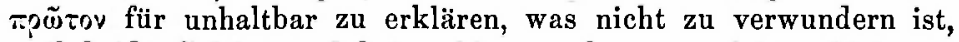
weil beide Gelehrten dabei wohl von der vorgefaßten Meinung ausgingen, daß die Einführung des provinzialen Kaisercultus in sämmtlichen Provinzen auf die frühere Kaiserzeit zu beziehen sei $^{35}$ ).

Führt also die übliche Altersbestimmung des narbonensischen Gesetzes auf ein kaum glaubliches Lebensalter des ersten Provinzialpriesters des narbonensischen Galliens, so muß man daraus schließen, daß dieselbe irrig ist

III.

Außer dem soeben angeführten, aus der athenischen Inschrift entnommenen Grunde kann man der herrschenden Meinung über die Abfassungszeit des narbonensischen Gesetzes auch einen anderen nicht weniger gewichtigen und zwar aus dem Gesetze selbst geschöpften Beweis entgegenstellen.

Soll der Provinzialcultus in Gallia Narbonensis schon unter

39) $\mathrm{Zu}$ diesen Ausnahmen mag die Aemtercarriere des Q. Licinius Venator gehören, welcher nach der Angabe eines von Mommsen ergänzten Lyoner Fragments (Boissieu p. 91 n. X = Esperandieu Inscr. de la cite des Lemovices, Paris 1891 , p. 217 n. 105) - sacerdotium apud aram duo et [viginti annos natus obtinuit], oder, wie es in einer anderen Inschrift desselben Priesters ebenfalls nach Mommsen's Ergänzung heißt, [qui duo et vi]ginti anno[s natus creatu]s sacerd[os est] (Boissieu p. $92=$ Esperandieu p. 219 n. 106). Uebrigens müchten wir für die letztere Inschrift mit Rücksicht auf die Größe des Lückenraumes vielmehr die folgende, von der Mommsen'schen nur formell abweichende Ergänzung vorschlagen: [Q. Licinio Verat]ori Licini [Taurici $f($ ilio $), \|$ cui duo et vi]ginti anno[s nato \| concili consensu]s sacerd[otium \| apud aram g]erere p[ermisit, \| tres pro]vinciae [Galliae], vgl. C. II 2344 omn(is) concil(ii) e[i] consensus statuam decrevit. Weniger wahrscheinlich sind mir Hirschfeld's Ergänzungen (Sitzungsber. S. 852 Anm. 86) wegen der denselben, wie es scheint, zu Grunde gelegten Annahme, daß Venator 22 Jahre lang das Provinzialpriesterthum bekleidet habe (vgl. Guiraud Les assembl. prov. S. 91 Anm. 1).

s) Bull. épigraph. IV S. 70.

s4) Les assembl. prov. S. 83 .

35. Vglhunten Cap. VIII. 
Augustus eingefülırt worden sein, so muß man annehmen, da $B$ der diesem Cultus gewidmete 'T'empel, der an melıreren Stellen des Gesetzes erwähnt wird ${ }^{36}$ ), noch bei Augustus' Lebzeiten errichtet ${ }^{37}$ ) und folglich dem Augustus in Gemeinschaft mit der Göttin Roma geweiht worden ist ${ }^{38}$ ). In diesem Falle aber würde der narbonensische Proviuzialpriester den Titel flamen, mit welchem er im Gesetze constant bezeichnet wird, schwerlich führen können. Denn dieser 'Titel ist mit Rücksicht auf die officielle Herkunft des provinzialen Kaisercultus ${ }^{39}$ ) wohl in dem Sinne aufzufassen, welchen er auf dem Gebiete des hauptstädtischen Sacralwesens hatte; anf diesem Gebiete aber palte er bekanntlich nur für denjenigen Priester, der sich dem Cultus einer einzigen Gottheit widmete. Wenn also dem narbonensischen Provinzialpriester wirklich der gemeinsame Cultus der Göttin Roma und des Augustus obgelegen hätte, so müßte er im Gesetze anstatt flamen vielmelir etwa sacerdos heißen.

Geben wir aber zu, daß der Titel flamen in unserer Urkunde der hauptstädtischen Sacralnomenclatur zuwider incorrect für sacerdos gebraucht wird. so müßte der vollständige Titel des Provinzialpriesters doch jedenfalls flamen Romae et Augusti lauten; es nennt ihn aber die einzige Stelle des Gesetzes, in welcher sein Titel vollständig angegeben wird, nur flamen Augus[talis] (Z. 21).

Freilich ist das Original gerade an der fraglichen Stelle verstümmelt, aber es ist nicht zu bezweifeln, daß die Ergänzung Augus [talı] die einzig richtige ist $\left.{ }^{40}\right)$. Denn, einerseits, wäre die Lesung fiamini Augus[ti et Romae] deshalb undenkbar, weil diese Wortstellung der officiellen Sprache durchaus fremd war. Die Wortstellung Romae et Augusti war namentlich in der westlichen Hälfte des römischen Reichs ${ }^{4 I}$ ) selbst außer dem Gebiete des

36) Z. 13: [Narbo]ne intra fines eius templi; vgl, auch Z. 30 u. 28.

${ }^{37}$ ) So meint z. B. Hirschfeld Sitzungsber. S. 840 Anm. 33.

sa) Vgl. oben Cap. I, wo Sueton. Aug. 52 angeführt ist. So ergänzt Alibrandi in ZZ. 7 und 23, auch in Z. 28: [in templo (bzw. templum) Romae et Augusti].

39) Man ziehe außerdem in Betracht die unten in Anm. 42 u. 43 angeführten Inschriften.

10) Sie ist zuerst von Mommsen und Hirschfeld vorgeschlagen worden; nur fassen sie den Titel famen Augustalis anders als wir auf: sie beziehen denselben, ihrer Ansicht über das Alter des narbonensischen Gesetzes gemäß, auf den Priester des lebenden Augustus und deuten ihn also in dem Sinne, den die Titel dieser Art in der municipalen Sacralnomenclatur haben (fam. Augustalis = flam. Augusti, vgl. darüber meine Diss. $\S 15 \mathrm{~S} .12 \mathrm{f}$.), während wir unter diesem flamen Augustalis einen flamen divi Augusti verstehen (vgl. darüber dieses Capitel a. E.). Andere ergänzen in Z. 21 Augus[ti], wovon unten die Rede sein wird.

Brougheinzige uns bekannte Ausnahme ist die folgende Inschrift, 
officiellen Sprachgebrauchs eine streng beobachtete Regel ${ }^{42}$ ): um so auffallender würde die Erwähnung der Göttin Roma nach der des Augustus gerade im narbonensischen Gesetze sein, wenn das Letztere wirklich von Augustus selbst herrühren soll ${ }^{43}$ ).

die kein officielles Document ist, C. V 3936: Q. Caicilio Cisiaco Septicio Picai Caciliano... flamini divi Aug(usti) et Roma C. Ligurius L.f. Vol. Asper (centurio) coh. I c(ivium) R(omanorum) infenuor(um). Da diese Inschrifi von einem Centurio dediciert worden ist, so braucht man wohl nicht etwa einen Fehler des Steinmetzen darin zu erblicken, denn auch sonst pflegten ja die Militairs sich um civile Titulaturen wenig $\mathrm{zu}$ bekümmern. - In den griechischen Inschriften sind solche Abweichungen von der officiellen Wortstellung ebenfalls selır selten: so kommen ujuvoo in einer pergamenischen zu Ehren Hadrians gesetzten Inschrift vor (vgl. IIirschfeld Sitzungsber. S. 837 Anm. 22); andere Beispiele sind oben in Anm. 16 u. 17 angeführt.

${ }^{42}$ ) Die äußerste Seltenheit der Wortstellung Augusti et Romae und noch mehr die Nichterwähnung der Göttin Roma im vollständigen Titel des narbonensischen Provinzialpriesters sprechen für die Richtigkeit der Hirschfeld'schen Ergänzung einer anderen Inschrift, die uns ebenfalls von der Dedication des narbonensischen Provinzialtempels unterrichtet: es ist C. XII 392: .... I [omnibus honorlhus] functo in $\|$ [patria sua, tribumo militum \|. . . ., [praefect]o alae Longi i [nunae, sucerdoti] templi divi $\|$ [Aug(usti), quod est Nar]bone, in quod [sacerdotium uni]cersa provinl[cia consentiente el]ectus est. Zwar gestattet der Lückenraum in Z. 6 anstatt quod est auch et Romae zu ergänzen, doch ist diese Ergänzung mit Rücksicht auf die obigen Gründe sicher nicht zu billigen. Statt sacerdoti möchten wir in Z. 5 lieber flamini ergänzen. Electus aber lesen wir a. E. statt des von Hirschfeld augenscheinlich nach Analogie der sardinischen Inschriften C. X 7917 u. 7940 vorgeschlagenen adlectus, weil die Ergänzung sacerd(os) in diesen letzteren nicht nur unsicher ist, sondern auch zu der ganz unwahrscheinlichen Annahme nöthigt, daß das Recht, den Provinzialpriester zu ernennen, in Sardinien im Gegensat\% zu den übrigen Provinzen nicht den Provinziallandtage, sondern dem Municipalrathe der Hauptstadt Carales zustand (vgl. Hirschfeld Sitzungsber. S. 854). Es handelt sich in diesen beiden Inschriften offenbar um die Aufnahme in die Rangclasse der sacerdotales, weshalb in C. X 7917 sac[er]d(otali) zu lesen ist; die Möglichkeit dieser Erklärung hat Hirschfeld ebend. Anm. 93 in Abrede gestellt, ohne jedoch Gründe dafür anzuführen. Der in C. X 7940 erwähnte Titel aber lautete wahrscheinlich [sacerdotalis] urb(is) Rom(ae et) im[p(eratoris)] prot(inciae) Sard(iniae), wie ich schon in meiner Diss. S. $64 \mathrm{Anm}$. 44 mit Rücksicht auf andere Beispiele solcher in den Priestertiteln vorkommenden asyndetischen Verbindungen vermuthet habe; zum Gebrauch des Wortes imperator vgl. C. III suppl. 7760.

$\left.{ }^{49}\right)$ Daß die Göttin Roma im provinzialen Kaisertempel der Gallia Narbonensis auch in späterer Zeit nicht mitverehrt wurde, kann man aus der folgenden Inschrift schließen, C. XII 4323: tauropolium provinciae Narbonensis factum per C. Batonium Primum flaminem Augg. pro salute dominorum impp. L. Septimi Severi ... et M. Aureli Ant(onini) Aug. In C. XII 4393 a liest Allmer [fam(ini)] primo [Aug. templit] novi Narbo[nens(is)] und ebendas. $b$. 19 sq. - ante ante aedem 
Andererseits verdient auch die Ergänzung Augus $[t i]$ keinen größeren Beifall. Der Urheber derselben, Heron de Villefosse ${ }^{4 k}$ ), sagt nicht, welchen Kaiser or unter diesem Augustus versteht. Mispoulet, der dieselbe Ergiinzung beibehalten hat ${ }^{\mathbf{5}}$ ), bezieht den obigen Namen auf den divus Augustus und hält es für möglich, das Fehlen der Bezeichnung divus dadurch zu erklären, daß in der Zeit, welcher er das narbonensische Gesetz zuschreiben will, d. h. unter den drei nächsten Nachfolgern des Augustus, der Letztere der einzige consecrierte Kaiser war (6). Man wird jedoch diese Erklärung schwerlich billigen, denn es giebt zwar einige Inschriften, in denen der vergötterte Augustus einfach Augustus genannt wird ${ }^{47}$ ), doch kommt eine solche Auslassung des Wortes divus nur ausnahmsweise vor und wäre in einem Gesetze durchaus unglaublich. Uebrigens gewinnt die obige Ergänzung nicht an Wahrscheinlichkeit auch durch die correcte Auffassung des Wortes Augus[ti] (im Sinne: „der regierende Kaiser"), welche wir bei Guiraud finden ${ }^{48}$ ). Denn nimmt man an, daß dieser regierende Kaiser eben Augustus war, was auch Guiraud für das Wahrseheinlichste hältt ${ }^{49}$ ), so muß man die Worte flamini Augus [ti] in Z. 21 als einen ungenauen Ausdruck für famini (bzw. sacerdoti) Romae et Augusti betrachten, welche Ungenauigkeit dem Verfasser eines Gesetzes, geschweige denn dem Augustus selbst, sicherlich nicht zuzutrauen ist. Das Wort Augus[ti] aber auf einen anderen Kaiser zu beziehen hindert die oben angeführte Inschrift C. XII 392, die bezeugt, daß der Provinzialtempel dem divus Augustus allein gowidmet war $\left.{ }^{51}\right)$.

Ist nun die Lesung flamini Augus[tali] in Z. 21 gesichert, so frägt es sich, wie das Wort Augustalis in diesem Titel zu verstehen ist. Man ersieht aus dem unmittelbar vorher Gesagten, daß dieses Wort nicht, mit Beziehung auf den regierenden Kaiser, als dem Worte Augusti gleichbedeutend zu interpretieren ist. Ebenso wenig darf man demselben Worte die Bedeutung "Romae et Augusti" beilegen ${ }^{51}$ ), erstens weil eine solche Ungenauigkeit im Ausdruck bei Abfassung eines Gesetzes un-

[Augusti], doch sind die Ergänzungen Aug. und Augusti unsicher (vgl. $b, 29$ ).

44) Bulletin critique 1888 S. 113.

45) Bull. crit. 1888 S. 186 f. 196.

${ }^{46)}$ Bull. crit. 1888 S. 256.

47) Vgl. Mommsen's Anm. zu C. VIII 10018

48) Comptes rendus de l'Acad. des sciences mor. et polit. N. S. XXX (1888) S. 263 Anm. 2.

49) Comptes rendus 1. 1. S. 263.

so) S. oben Anm. 42.

$\left.{ }^{51}\right)$ So wird das fragliche Wort vielleicht von Alibrandi aufgefaßt, der an mehreren Stellen des Gesetzes [in templo Romae et Augusti] ergäuzt, vgl, oben Anm. 38.

Brolight to you by $\mid$. Université Paris Ouest Nanterre La Défense 
denkbar ist; zweitens weil das Wort famen auf den Cultus einer einzigen Gottheit hindeutet; es kommt noch hinzu, daß in der mehrmals citierten Inschrift C. XII 392 von der Mitverehrung der Göttin Roma im provinzialen Kaisertempel des narbonensischen Galliens keine Rede ist. Es bleibt also nichts übrig, als den fraglichen Titel im Sinne von flamen $d i v i A u$ g u s $t i, \mathrm{~d}$. h. in dem Sinne, welcher diesem Titel in der hauptstädtischen Sacralnomenclatur beigelegt wird, aufzufassen, womit auch die Thatsache der hauptstädtischen Herkunft des narbonensischen Gesetzes, wie des provinzialen Kaisercultus überhaupt vortreftlich übereinstimmt.

\section{IV.}

Wir sehen also, daß es mehr oder weniger wichtige Gründe giebt, die uns die herrschende Meinung über das Alter des narbonensischen Gesetzes als unhaltbar zu erklären veranlassen. Wenden wir uns nun der Prüfung der Beweise zu, mit welchen man die obige Meinung zu stützen sucht, so finden wir die betreffende Beweisführung in ihrer ursprünglichen Gestalt folgendermaßen von Hirschfeld formuliert: '[C. XII 6038] pars videtur esse legis, qua de concilio et de flamine provinciae sanctum fuit, datae, ni fallor, ab ipso imperatore Augusto (cf. v. 27), cum divi Augusti mentio non fiat' ${ }^{52}$ ). Aber es ist leicht zu ersehen, daß diese Argumentation unvollständig ist: denn man vermißit eine Auskunft darüber, warum von allen Kaisern wenigstens des ersten Jahrhunderts, deren Namen mit den Worten imperator Caesar (vgl. Z. 27) beginnen, Augustus allein in Betracht gezogen wird ${ }^{53}$ ).

Später versuchte man die obige Argumentation weiter zu entwickeln, indem namentlich Alibrandi behauptet hat, daß es am Ende von Z. 13 schwerlich einen für die Einschiebung des Namens Vespasianus bzw. Domitianus genügenden Raum gebe ${ }^{54}$ ). Er hat diese Behauptung offenbar mit Rücksicht darauf aufgestellt, daß eine jede Zeile des Gesetzes nach seiner Untersuchung ${ }^{55}$ ) im Durchschnitt etwa 100 Buchstaben enthielt ${ }^{56}$ ), Z.

${ }^{52}$ ) C. XII p. 864 , vgl. auch Sitzungsber. S. 848 Anm. 67.

63) Uebrigens findet die obige Beweisführung vielleicht ihre Ergänzung in der schweigend vorausgesetzten Annahme, daß der provinziale Kaisercultus überall schon in der frühen Kaiserzeit eingeführt worden sei. Vgl. darüber unten Cap. VIII.

54) Bull. dell' Istit. di diritto rom. I p. 179.

b5) Sein Verfahren war dabei das Folgende: er hat eine gerade Linie durch die Mitte der Rubriken gezogen, die Buchstaben in den Zeilen, deren erstere Hälften unversehrt erhalten sind, von ihrem Anfang bis zur obigen Linie gezählt und das Doppelte dieser Zahlen für die annähernden Buchstabenzahlen der betreffenden Zeilen gehalten.

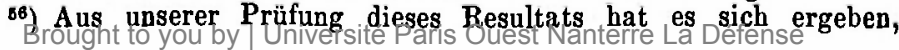


13 aber in seiner eigenen Redaction 97, in derjenigen von Mommsen und Hirschfeld 96 Buchstaben zählt ${ }^{57}$ ), also die durchschnittliche Buchstabenzahl fast erreicht.

Da jedoch die Zahl 100 eben nur eine durchschnittliche ist. so giebt es in formeller Hinsicht keinen Grund, die Einschaltung des Wortes Vespasianus nach dem Worte Caesar als unmöglich abzuweisen: denn die Letztere wird die Buchstabenzall der fraglichen Zeile nur bis auf 108 bzw. 107 Buchstaben erhöhen ${ }^{58}$ ). Da aber Alibrandi selbst sonst kein Bedenken trägt, jene Durchschnittszahl (100) sogar um 13 Buchstaben zu überschreiten ${ }^{59}$, so erweist sich seine Behauptung, dab die Einschiebung des Wortes Vespasianus bzw. Domitianus in Z. 13 in Folge des Mangels an Raum unmöglich sei, schon auf Grund der obigen Berechnung als ganz willkürlich ${ }^{60}$ ).

\section{V.}

Es kann übrigens keine von den bisher vorgeschlagenen Redactionen der ersten Hälfte von Cap. 2 des Gesetzes (ZZ. 10-13), welch' letzterer auch die fragliche Stelle (Z. 13) angehört, als in aller Hinsicht befriedigend bezeichnet werden.

Was nun zunächst die Alibrandi'sche Redaction anbetrifft, die folgendermaßen lautet: $[S i$ is qui flamen fue $]$ rit adversus hanc legem nihil fecerit, tum is qui flamen erit c[oncilio referto cum duac partes aderunt $\|$ ut per tabell]as iurati decernant placeatne ei qui flamonio abierit permitti sta[tuam ponere in templo . . $\left.{ }^{61}\right)$. Si id placue\|rit ei sta]tuae ponendae nomenque suum patrisque et unde sit et quo anno fa[men fuerit adscribendi ius esto; neve ali ex quo\|vis ordi]ne intra fines eius templi statuae ponendae ius esto nisi

daß dasselbe im Allgemeinen als richtig zu bezeichnen ist. Irrig hält Mispoulet (Bullet. crit. 1890 p. 11) die Zahl 100, im Widerspruch mit der ausdrücklichen Erklärung von Alibrandi selbst, für die maximale, indem er überdies ganz willkürlich 90 als die minimale angiebt.

${ }^{57}$ ) Die beiden Redactionen sind in Cap. V angeführt.

s8) Schiebt man aber das Wort Domitianus ein, so erhöht man dadurch die obige Buchstabenzahl bis auf 107 bezw. 106 Buchstaben. ${ }^{88}$ ) So enthält Z. 27 mit seinen Ergänzungen gerade 108, Z. 8 aber sogar 113 Buchstaben. Und er hat gewiß darin vollkommen Recht, daß er sich an jener Durchschnittszahl nicht allzu ängstlich festhält, denn es sind weder alle Buchstaben (vgl. unten Anm. 80), noch Zwischenräume $\mathrm{zwischen}$ denselben gleich groß.

$\left.{ }^{60}\right)$ Wir werden dies unten (Cap. VI) mit Evidenz nachweisen.

61) Nach dem Worte templo läßt Alibrandi absichtlich eine Lücke, iur deren Ergänzung er mehrere Lesungen vorschlägt, und zwar: sipra) 8 (cripto) - Rom(ae) et Aug(usti) - novo - provinciae, ohne slch zur definitiven Auswahl irgend einer von denselben zu entschließ̉en

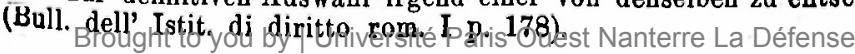


cui imperator [Caesar Augustus permiserit. Item ę] u. s. w. so beschränken wir uns darauf, den Leser auf Mispoulet's Kritik zu verweisen ${ }^{62}$ ).

Die Mommsen-Hirschfeld'sche Redaction, mit welcher die Mispoulet'sche ${ }^{63}$ ) im Großen und Ganzen übereinstimmt, lautet wie folgt: [Si qui flamen fue]rit adversus hanc legem nihil fecerit,

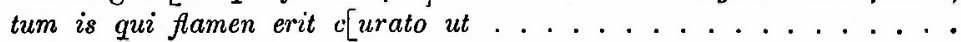
. II per tabell]as $\left.{ }^{64}\right)$ iurati decernant placeatne ei qui flamonio abierit permitti sta[tuam sibi ponere. Cui ita decreverint \| ius esse sta]tuae ponendae nomenque suum patrisque et unde sit et quo anno fa[men fuerit inscribendi, ei \| Narbo]ne intra fines eius templi statuae ponendae ius esto, nisi cui imperator [Caesar Augustus interdixerit. Eidem] u. s. w. Die Alibrandi'sche Kritik derselben bezieht sich eigentlich auf deren stilistische Fassung und ist nicht in allen Punkten ïberzeugend ${ }^{65}$ ). Wir aber haben gegen diese Redaction das einzuwenden, daß einerseits die kaiserliche Prïrogative, die Beschlüsse der Provinzialversammlungen zu annullieren, im betreffenden Falle wohl keiner Einschärfung durch eine specielle Clausel bedurfte; andererseits, daß eine ausdrückliche Sicherung des Rechtes des gewesenen Flamens, gegen obige Beschlüsse an den Kaiser zu appellieren, nicht leicht entbehrt werden konnte. Auch würde eine specielle Erwähnung des Kaisers als der höchsten Appellationsinstanz für gewesene Provinzialpriester an dieser Stelle sehr erwünscht sein, theils deshalb, weil man in der Person des Provinzialstatthalters eine andere Instanz zur Entscheidung über manche den Provinziallandtag betreffende Angelegenheit hatte $\left.{ }^{66}\right)$; theils da das narbonensische Gallien bekanntlich zu den Senatsprovinzen gehörte, für welche ja eigentlich der Senat selbst wenigstens de iure die höchste Instanz bildete.

In Folge dieser Erwägungen möchten wir unsererseits die

$\left.{ }^{82}\right)$ Bullet. critique 1890 S. 7 f.

$\left.{ }^{89}\right)$ Bull. crit. 1888 S. 186.

${ }^{64)}$ Die Ergänzung der Lücke von Z. $10 \mathrm{f}$. lautet im Corpus also: e[urato per duoviros ut . . . . II decurione $]$ s (C. XII 6058). Später hat Hirschfeld (Sitzungsber. S. 859 Anm. 123) mit Rücksicht auf Mispoulet's Bemerkungen (Bull. crit. 1888 p. $257 \mathrm{sq}$.) des Letzteren Lesung [per tabell]as gebilligt und außerdem anerkannt, daß es sich an der fraglichen Stelle nicht um die Decurionen (von Narbo), sondern um die Mitglieder der Provinzialversammlung handelt. Dagegen halten Mommsen und Gradenwitz an der im Corpus stehenden Ergänzung in der 6. Auflage der Fontes iur. Rom. von Bruns I (Frib. 1893) p. 141 fest, obwohl das am Anf. von Z. 11 erhaltene AS (vgl. Mispoulet Bull. crit. 1890 S. 6) die Lesung decurionee wenigstens an dieser Stelle ausschließt. Mispoulet aber liest ebendaselbst: $c[u m$ abierit, ad legatos referat iique per tabell]as u. s. w. (Bull. crit. 1888 p. 186).

65) Bull. dell' Istit. di diritto rom. I p. 179.

${ }^{68}$ Bgl. Z. 28 des Gesetzes. 
folgende neue Redaction der fraglichen Stelle empfehlen: [Si is qui flamen fue]rit adversus hanc legem nihil fecerit, tum is qui flamen erit c[oncilium Narbone in templo divi Augusti cogito ${ }^{67}$ ), $\|$ ut per tabell]as iurati decernant placeatne ei qui flamonio abierit permitti sta[tuam Narbone intra fincs eius templi ponere. Si pla\|cuerit ${ }^{68}$ ), ei sta]tuae ponendae nomenque suum patrisque et unds sit et quo anno fla[men fuerit inscribendi ius esto; si minus, tum nulli ${ }^{69} \|$ Narbo]ne intra fines eius templi statuae ponendas ius esto, nisi cui imperator [Caesar Vespasianus Augustus concesserit ${ }^{70}$ ). Ei$\left.\left.q u e^{11}\right)\right]$ u. s. w. In dieser Gestalt enthält Z. 13 eine noch kleinere Zahl von Buchstaben, als bei Alibrandi und Hirschfeld, und zwar 106 oder 105, je nachdem wir concesserit oder permiserit lesen. Zwar ist es möglich diese Zahl auf eine noch geringere $\mathrm{zu}$ reducieren ${ }^{7 *}$ ), aber es ist keineswegs nothwendig: denn unsere Ergänzung der fraglichen Zeile entspricht, wie wir es gleich nachweisen werden, der Größe des auszufüllenden Raumes ziemlich genau; das gilt auch für die beiden übrigen eben angeführten Ergänzungen, wenn man dieselben durch die Einschaltung des Wortes Vespasianus modificiert.

Um dies nun nachzuweisen, hat man zunächst die Länge der Zeilen der narbonensischen Bronzetafel wenigstens annähernd zu bestimmen, wobei man von der Voraussetzung ausgehen muß, dals die Rubriken der Urkunde genau gegen die Mitte der übrigen Zeilen derselben stelsen ${ }^{73}$ ).

Die Zeile 18 von ihrem Anfang bis zu der Stelle, wo über derselben die Rubrik (Z. 17) beginut, ist 15,5 Centimeter lang ${ }^{71}$ ). Ebenso lang war offenbar die Fortsetzung von Z. 18 nach dem Schlusse der über derselben steheuden Rubrik. Diese nun hatte im Ganzen die Länge von etwa $20 \mathrm{Cm} .{ }^{35}$ ), und ebenso lang war augenscheinlich auch der ihr entsprechende mittlere Theil

${ }^{67)}$ Oder etwa convocato.

$\left.{ }^{68}\right)$ Oder etwa so: si id de\|creverint.

${ }^{69}$ ) Oder wohl ne cui.

${ }^{70}$ ) Oder wohl permiserit.

7x) Oder etwa tum ei.

${ }^{72}$ ) So z. B. kanu man a. E. et statt eique ergänzen, wodurch die Buchstabenzahl von Z, 13 fast auf die Durchschnittszahl (100) herabgesetzt wird.

${ }^{73}$ ) Es unterliegt keinem Zweifel, daß diese Vornussetzung richtig ist, vgl. Hirschfeld zu C. XII 6038 und Alibrandi l. l. p. 175.

$\left.{ }^{74}\right)$ Zur Ausfübrung der Messungen, deren Resultate hier mitgetheilt werden, haben wir einen Abklatsch der narbonensischen Tafel benutzt.

$\left.{ }^{76}\right)$ Der erhaltene Theil der Rubrik (Z, 17), welche lautet: si flamen

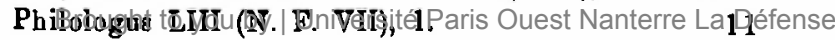


von Z. 18. Addiert man nun $15,5+20+15,5$, so bekommt man 51, welche Zahl die Länge sowohl der fraglichen Zeile als überhaupt jeder, die unmittelbar auf die Rubriken folgt, in Centimetern ausdrückt. Da jedoch wohl keine besondere Sorgfältigkeit des Graveurs bei Abmessung der freien Räume vor und nach den Rubriken vorauszusetzen ist ${ }^{76}$ ), so kann man die obige Zeilenlänge nur für annähernd halten und dieselbe event. etwa um $1 \mathrm{Cm}$. höher berechnen $(52 \mathrm{Cm}$.). Die übrigen Zeilen, die um 1 bzw. 1,2 Cm. kürzer als jene auf die Rubriken folgenden sind, müssen demgemäß zu 50 event. $51 \mathrm{Cm}$. berechnet werden ${ }^{77}$ ).

$\mathrm{Da}$ nun eine detaillierte Untersuchung ${ }^{78}$ ) zeigt, daß im Durchschnitt je zwei Buchstaben auf Einen Centimeter kommen ${ }^{7 y}$ ),

in civitate esse des[ierit], nimmt einen Raum von $17,5 \mathrm{Cm}$. ein; auf ihre Endlücke kommen $2,5 \mathrm{Cm}$, und zwar so berechnet: die Länge der ergänzten Buchstaben selbst (ierit) macht etwa 1,5 Cm. (nämlich $0,1+0,4+0,5+0,1+0,4)$ aus, $5 \mathrm{Zwischenräume} \mathrm{zwischen} \mathrm{den}$ Buchstaben aber erfordern den Raum von ca. $1 \mathrm{Cm}$. Die Richtigkeit dieser Berechnung wird durch die Vergleichung der Länge einzelner Wörter der Rubrik mit der derselben Wörter in Z. 18, wo die ganze Rubrik wiederholt ist, bestätigt. So nimmt das Wort flamen einen Raum von $4,2 \mathrm{Cm}$. in der Rubrik (Z. 17) und von $3,1 \mathrm{Cm}$. in Z. 18 ein, das Wort civitate $-4,2 \mathrm{Cm}$. in $\mathrm{Z} .17$ und $3,4 \mathrm{Cm}$. in Z. 18 . Die erhaltenen Anfangsbuchstaben (DES) des letzten Wortes der Rubrik haben insgesammt die Länge von ca. $1,6 \mathrm{Cm}$, das ganze Wort aber muß nach unserer Berechnung etwa $4,1 \mathrm{Cm}$. lang sein (d. h. $1,6+2,5):$ da nun dasselbe in $\mathrm{Z}$. 18 einen Raum von ca. $3,2 \mathrm{Cm}$. einnimmt, so bekommen wir augenscheinlich eben dasselbe Längeverhältniß zwischen dem des[ierit] der Rubrik und dem desierit von Z. 18, wie bei den übrigen Wörtern der Ersteren und ihren Wiederholungen in der Letzteren.

$\left.{ }^{76}\right)$ Man ziehe nur den unverbältnißmäßig großen $(1,5 \mathrm{Cm}$.) Zwischenraum zwischen den Wörtern esse und des[ierit] in der fraglichen Rubrik selbst (Z. 17) in Betracht.

77) Dieses Ergebniß stimmt mit dem Resultat von Alibrandi, daß eine jede Zeile des Gesetzes durchschnittlich 100 Buchstaben enthielt, gut überein, da für 100 Buchstaben ein Raum von ungefähr $50 \mathrm{Cm}$. erforderlich ist, wie wir es gleich sehen werden.

$\left.{ }^{78}\right)$ Die Resultate derselben sind folgende: in Z. 2 finden wir auf dem (noch erhaltenen) Raume von $7 \mathrm{Cm} .13$ Buchstaben; in Z. 3 : $11 \mathrm{Cm} .-21 \mathrm{~B}$; in Z. $4: 11,5 \mathrm{Cm} .-24 \mathrm{~B}$; in Z. $5: 15 \mathrm{Cm}$. $-31 \mathrm{~B}$.; in Z. $6: 16-33$; in Z. $7: 18-36$; in Z. $8: 20-43$; in Z. 10 : $25-51$; in Z. $11: 27-57$; in Z. $12: 29-54$; in Z. $13: 31-60$; in Z. $14: 33-64$; in Z. $15: 33-67$; in Z. $16: 32-66$; in Z. 18 : $31,7-61$; in Z. $19: 28,4-55$; in Z. $20: 26,8-45$; in Z. 21 : $25-44$; in Z. 23: $20,8-36$; in Z. 24: $18-34$; in Z. 26: $17,2-31$; in Z. $27: 15-27$; in Z. $28: 14-25$; in Z. 29 (von RE an): $11-21$. Die erste Hälfte der Urkunde ist etwas knapper als die zweite geschrieben, wie dies auch aus den obigen Zahlen erhellt.

79) Genau so in der uns speciell interessierenden ersten Hälfte der Urkunde: ZZ. 2-14, sofern sie erhalten sind, haben die Gesammtlänge von $243,5 \mathrm{Cm}$. und enthalten 487 Buchstaben. 
so umfaßt ein Raum von $51 \mathrm{Cm}$. durchschnittlich 102 Buclıstaben: es ist also schon jetzt klar genug, daß wenigstens unsere Redaction von Z. 13 mit ihren 105 bzw. 106 Buchstaben ohne besondere Schwierigkeit im betreffenden Raume Platz finden kann ${ }^{80}$ ).

Doch besitzen wir überdies ein Mittel, die formelle Möglichkeit der Einschaltung des Wortes Vespasianus in Z. 13 und zwar mit noch größerer Evidenz nachzuweisen.

$\mathrm{Zu}$ diesem $\mathrm{Zwecke}$ müssen wir zunächst die Dimension der (rechten) Lücke der obigen Zeile möglichst genau feststellen, was keine besondere Schwierigkeit bietet, da wir die Länge der ganzen Zcile $(50 \mathrm{bzw}$. $51 \mathrm{Cm}$.) schon wissen, die Lücke aber vom Anfang der Zeile etwa $33 \mathrm{Cm}$. weit absteht, wie dies ebenfalls leicht zu bestimmen ist. Subtrahiert man die zweite Zahl von der ersteren, so bekommt man $17 \mathrm{bzw}$. 18, welche Zahl die Länge der fraglichen Lïcke in Centimetern darstellt. Es bleibt uns nun übrig zu controlieren, ob dieser Raum der von uns . vorgeschlagenen Ergänzung der Lücke entspricht.

Auf Grund detaillierter Messungen einzelner Buchstaben bzw. Buchstabengruppen können wir constatieren, daß unsere Redaction der fraglichen Stelle: [Caesar Vespasianus Augustus concesserit (bzw. permiserit). Eique] einen Raum von ca. 18 bzw. $17,7 \mathrm{Cm}$. erfordert ${ }^{81}$ ).

Setzen wir aber nach dem Worte Augustus mit Alibrandi : permiserit. Item ei, so kommt die Länge der ergänzten Stelle ungefähr 18,2 $\mathrm{Cm}$. gleich ${ }^{82}$ ).

Lesen wir endlich ebendaselbst mit Mommsen und Hirsch-

$\left.{ }^{80}\right)$ Man erinnere sich namentlich an die ungleiche Größe einzelner Buchstaben, die von $0,1 \mathrm{Cm}$. (I) bis $0,7 \mathrm{Cm}$. (M) variiert. Vgl. außerdem hinsichtlich der Buchstabenzahlen Z. 14 mit Z. 15, Z. 16 mit Z. 18, auch Z. 3 mit Z. 4 und Z. 7 mit Z. 8 (oben Anm. 78).

81) Und zwar erfordert (bei der Lesung concesserit) die Gruppe CAE $1,3 \mathrm{Cm}$. (so in Z. 27 a. E.), CONC - 1,8 Cm. (so in ZZ. 14 . 23. 24), ESS - $1 \mathrm{Cm}$. (so in Z. 18), ERIT - 1,6 Cm. (so in ZZ. 10 . 11. 16. 18. 19), EIQVE $-2 \mathrm{Cm}$. (so in Z. 8, vgl. auch Z. 15) an Raum; ferner sind $7,7 \mathrm{Cm}$. für den Rest der Ergänzung [sar Vespasianus Augustus] erforderlich, bei der folgenden maximalen Breite der einzelnen Buchstaben in Cmn.: A, V, R, T je 0,$4 ; E, G, P, S$ je 0,3 ; $\mathrm{N}-0,5 ; \mathrm{I}-0,1$; es kommen endlich $2,6 \mathrm{Cm}$. für $26 \mathrm{Zwischenräume}$ zwischen den einzelnen Buchstaben hinzu, diejenigen der oben angegebenen Buchstabencomplexe natürlich nicht miteinbegriffen. - Permiserit $(2,6 \mathrm{Cm}$.) ist um $0,3 \mathrm{Cm}$. kürzer als concesserit $(2,9 \mathrm{Cm}$.), wie dies auf Grund der soeben angegebenen Breite der einzelnen Buchstaben leicht zu berechnen ist (vgl, auch Anm. 80).

${ }^{82}$ ) Das Wort ifem ist ca. $1,9 \mathrm{Cm}$. lang (so in Z. 15) und kommt also, nebst dem unmittelbar darauf folgenden $Z$ wischenraume $(0,1 \mathrm{Cm}$.) ganz dem Worte eique (s. oben Anm. 81) gleich; man muß demgemäß zu $17,7 \mathrm{Cm}$. nur die Länge von ei $(0,5 \mathrm{Cm}$.) hinzufügen. 
feld : interdixerit. Eiclem, so nimmt die betreffende Ergänzung einen Raum von etwa 18,6 Cm. in Anspruch ${ }^{83}$ ).

Es fügen sich also die oben angeführten Ergänzungen ziemlich genau in den Lückenraum ein. Somit fällt das wichtigste Argument, womit Alibrandi und nach ihm Beurlier ${ }^{81}$ ) die herrschende Meinung über die Entstehungszeit des fraglichen Gesetzes zu bekräftigen suchten. $\mathrm{Ja}$, man muß jetzt gerade das Gegentheil anerkennen, nämlich daß die üblichen Ergänzungen der rechten Lücke von $Z$. 13 eben deshalb als mangelhaft zu bezeichnen sind, weil dieselben den ganzen Raum der Lücke nicht ausfüllen: in der That erfordert die von Mommsen und Hirschfeld vorgeschlagene Ergänzung nur 13,8 Cm., die von Alibrandi aber nur $13,4 \mathrm{Cm} .{ }^{85}$, welche Zahlen selbst für die Minimallänge der Lücke $(17 \mathrm{Cm}$.) zu klein sind.

Zugleich erhält unsere Bestimmung des terminus a quo der Abfassung des narbonensischen Gesetzes eine sichere formelle Begründung. Da nämlich einerseits die oben entwickelten aus der athenischen Inschrift des Q. Trebellius Rufus sowie aus Z. 21 des Gesetzes selbst entnommenen Gründe die Annahme der Herkunft des Letzteren aus der augusteischen Zeit ausschließen; andererseits aber Vespasianus bekanntlich der Erste unter den Nachfolgern des Augustus ist, dessen Name mit den Worten imperator Caesar beginnt ${ }^{86}$ ), so kann der in ZZ. 13 und 27 theil-

83) Das Wort interdixerit ist um $0,5 \mathrm{Cm}$. länger als concesserit, da CONCESS $2,9 \mathrm{~cm}$. (s. oben Anm. 81), INTERDIX aber $3,4 \mathrm{Cm}$. lang ist; es sind nämlich für INTER $2,3 \mathrm{Cm}$., wìe in $\mathrm{Z}$. 14, und für DIX $1 \mathrm{Cm}$. erforderlich, indem $D$ etwa $0,3 \mathrm{Cm}$., $X$ etwa $0,4 \mathrm{Cm}$. breit ist; $\mathrm{zu} 2,3+1,0$ haben wir noch $0,1 \mathrm{Cm}$. für den $\mathrm{Z}$ wischenraum $z$ wischen INTER und DIX hinzugefügt. Das Wort eidem nimmt nach der normalen Bereclınung einen Raum von ca. $2,1 \mathrm{Cm}$. ein (in Z. 28 ist IDEM allein $2 \mathrm{Cm}$. lang), d. h. ist um $0,1 \mathrm{Cm}$. länger als eique (s. oben Anm. 81). Ersetzen wir also die Worte concesserit, eique durch interdixerit, eidem, so vergrößert sich dadurch die Länge der Lückenergänzung um $0,6 \mathrm{Cm}$.

84) Le culte impirial S. 22: Pour trouver un empereur autre qu'Auguste dont le nom commence directement par Imperator Caesar, il faudrait descendre jusqu'à Vespasien. Il est plus simple de s'en tenir à Auguste lui-meme, surtout si l'on observe que la place manquerait pour inscrire tout au long les titres de Vespasien à la ligne 13 .

${ }^{85}$ ) Es sind von $18,6 \mathrm{bzw}, 18,2 \mathrm{Cm}$. (s, oben im Text) 4,8 $\mathrm{Cm}$. abzuziehen, wovon $4,7 \mathrm{Cm}$. auf das Wort Vespasianus und $0,1 \mathrm{Cm}$. auf einen $Z w i s c h e n r a u m$ kommen.

86) Die ähnliche, nur ausnahmsweise vorkommende Titulatur des Tiberius, imp. Caesar (divi) Augusti flius Augustus, kommt natürlich hier nicht in Betracht (vgl. Mommsen Slautsrecht II ${ }^{3}$ S. 769 und zu C. VIII 10018). Beiläufig bemerken wir, daß es in C. VIII 10023 (vgl. 10018; wohl gehört auch n. 5205 dazu) folgendermaßen zu lesen ist: imp(erator) Caes(ar) Augusti f(ilius) Augustus tri(bunicia) pot(estate) $X V I$, Asprenas cos., pr(o) cos., VII vir epulonum riam ex cast(ris)

Brought to you by |Université Paris Ouest Nanterre La Défense 
weise erhaltene Kaisertitel ${ }^{87}$ ) sich auf keinen Vorgänger des Vespasianus beziehen und das fragliche Gesetz nicht vor dem J. 69 , d. h. nicht vor der Thronbesteigung Vespasians, erlassen $\operatorname{sein}{ }^{88}$ ).

\section{VII.}

Wir haben bisher nachzuweisen gesucht, daß die Einschaltung des Namens Vespasianns in Z. 13 des Gesetzes formell möglich ist. Nunmehr wollen wir die Namen der übrigen Kaiser in Betracht ziehen, die in gleichem Maße wie Vespasianus die Ehre der Einführung des Provinzialcultus im narbonensischen Gallien beanspruchen zu können scheinen.

Die Lösung der Frage aber, welche Kaiser außer Vespasianus unter dem obigen Gesichtspunkte in Betracht kommen können, hängt natürlich vom Ansatz des terminus ad quem der Entstehung des fraglichen Gesetzes ab. Zwar gilt als dieser terminus schon das Jahr 126 , welches die späteste Zeitgrenze der Abfassung der oben besprochenen athenischen Inschrift bildet ${ }^{89}$ ), doch kann man denselben noch genauer feststellen, und zwar auf Grund der folgenden nemausischen Inschrift, C. XII $3212^{\text {add. }}$ : M. Cominio M. f. Volt. Aemiliano eq(uum) p(ublicum) habenti curat [o]ri Aquensi $c$ [oloniae] dato ab imp(eratore) $T[$ rai(ano), fla]mini provinc(iae) $[\mathrm{Narb}($ onensis $)]$, flam(ini) co[l(oniae) $]$ Au[g(ustae) Nem(ausensium), IIII vir(o)] ab aer(ario), po[nt(ifici)], pra[e]f(ecto) $[v i g($ ilum $)]$. So lautet diese Inschrift nach der letzten Revision von Hirschfeld ${ }^{90}$ ), der frïher glaubte, es sei in Z. 6 [ Hadr(iano)] zu lesen, weil er damals im Original nur IM/ $\mathbf{I} / / / /$ wahrgenommen hatte. Da es nun aber ganz sicher steht, dab der unmittelbar auf das Wort imp(eratore) folgende Buchstabe nicht ein $\mathrm{H}$, sondern ein $\mathbf{T}$ war, so ist daselbst offenbar entweder Trajans Name, was Hirschfeld annimmt ${ }^{91}$ ), oder derjenige von Titus zu ergänzen, d. h. man muß entweder $a b$ imp. $\left[T_{r}\right] a[i($ ano $)]$ oder $a b$

hibernis Tacapes muniendam curavit leg(ione) III Aug(usta), - oder, um das Asyndeton zu vermeiden, wohl auch so: imp(eratore) Caes(are) man beachte das in $\mathrm{n} .5205$ (handschriftlich) überlieferte CAESARI Augusti f(ilio) August[o] u. s. w., wodurch alle von Mommsen (zu C. VIII 10018) angegebenen Schwierigkeiten betreffs der stilistischen Fassung der fraglichen Inschrift ziemlich einfach beseitigt werden. Die Worte leg(ione) III Aug(usta) sind natürlich als abl. instrum. aufzufassen, vgl. z. B. Caes. $B$. $G$. 1,8,1.

87) Vgl. oben Cap. I am Anfang.

${ }^{88)}$ So haben wir den fraglichen terminus a quo schon in unserer Dissertation $S .66$ angesetzt.

Bo) $\nabla$ gl. oben Cap. II.

$\left.{ }^{\circ 0}\right)$ ' $V .6$ ex., sagt er C. XII p. 836, videtur esse $T$ '.

') Vgl. C. XII 1. l. und p. 931 col. 2.

Brought to you by | Université Paris Ouest Nanterre La Défense 
imp. $[T(i t o)] A[u g(u s t o)]$ lesen, nämlich mit Heranziehung der Allmer'schen Copie, deren Angaben sich sehr wohl mit denen von Hirschfeld combinieren lassen ${ }^{92}$ ).

Ist nun unsere Ergänzung des obigen Kaisernamens richtig ${ }^{9: 1}$ ), so giebt sie eine definitive Entscheidung der Frage, wolchem Kaiser die Einfïllrung des Provinzialcultus in Gallia Narbonensis oder, mit anderen Worten, die Erlassung des narbonensischen Gesetzes zuzuschreiben ist. Wir haben oben gezeigt, daß dieses Gesetz frühestens von Vespasian herriihren muß. Da aber die Inschrift des M. Cominius Aemilianus (bei unserer IJesung von Z. 6) das Bestehen des narbonensischen Provinzialcultus schon unter 'Titus' Regierung bezeugt, und es, andercrseits, unmöglich ist, den Titus selbst für den Urheber des fraglichen Gesetzes zu halten, weil der Titel dieses Kaisers bekanntlich nicht mit den Worten imperator Caesar beginnt, so liegt es am Tage, daß das obige Gesetz das Werk des Vespasianus und keines Anderen ist ${ }^{94}$ ).

92) Allmer hat an der fraglichen Stelle AB IMP /// A ///// gelesen.

23) Es ist zu beachten, daß nach Allmer's Angabe nur Ein Buchstabe $\mathrm{zwischen}$ IMP und $\mathrm{A}$ in Z. 6 verloren gegangen ist (Revue épigraph. I p. 138). Ist dies richtig, so verliert Hirschfeld's Ergänzung im Vergleich mit der unsrigen etwas an Wahrscheinlichkeit, da man bei der ersteren zwei Buchstaben (TR) an der fraglichen Stelle einschieben muß; wenigstens glauben wir nicht, daß Allmer irriger Weise $A$ statt $\mathrm{R}$ gelesen hat.

84) Ein zweiter Schluß, den man aus unserer Lesung ziehen darf, betrifft die Frage über die Entstehungszeit des Instituts der curatores rei publicue. Man glaubte früher, daß die ältesten Beispiele dieser Curatel erst aus der traianischen Zeit nachweisbar sind (Mommsen Stats'echt $\mathrm{II}^{3}$ S. $1083 \mathrm{Anm}$. 1). Degner hat ein Beispiel aus der domitianischen Epoche angeführt, C. III $291=$ supplem. 6818: $\ldots$. P. f. Stel. Sosp[i]ti fetiali, leg. Aug. pro pr. provinc. Gal(atiue), Pisid., Phryg., Luc(aoniae), Isaur., Paphlag., Ponti Galat(ici), Ponti Polemoniani, Arm(eniae), leg(ato) leg. XIII Gem., donat(o) don(is) militari$b(u s)$ expedit(ione) Suebic(a) et Sarm(atica) . . . . curat(or) colonio$r(u m)$ [sic!] et municipion. (um) (betreffs der Deutung der letzten Worte vgl. unten Anm. 165). Er hat dicses Citat mit der folgenden Bemerkung begleitet: 'attamen .... cavendum est, ne ex illo titulo colligamus, a Domitiano ipso curatores esse institutos: praesertim cum iam antea cos fuisse tota ex tituli natura apparere videatur' (Quaestionis de curatore rei publicae pars prior, Hal. Sax. 1883 p. 14), und daß diese Warnung richtig ist, das bezeugt eine castulonensische, von Degner übersehene Inschrift, die einen curator divi $T i[t] i$ in Baetica erwähnt (C. II 3271, vgl. unten Cap. XIII). Die nemausische Inschrift aber liefert, wenn wir mit unserer Ergänzung derselben das Richtige getroffen haben, ein anderes Zeugrniß dafür, daß es schon unter Titus Gemeindecuratoren gab. Wir möchten übrigens selbst Titus' Regierung nicht für die älteste Zeitgrenze der Einrichtung der Gemeindecuratelen halten, sondern deren Ursprung aus der vespasianischen Epoche herleiten, da ein dringendes Bedürfniß nach einer derartigen aüßerordentlichen Maßregel wohl sofort nach den vorvespasianischen Unruhen
Brought to you by I Universite Paris Ouest Nanterre La Defense 
Wenn dagegen Hirschfeld's Ergänzung richtig ist, so führt sie uns auf das Todesjahr Trajans (117 n. Chr.) als den terminus ad quem der Abfassung des fraglichen Gesetzes. Demzufolge muß Einer von den folgenden vier Kaisern: Vespasian, Domitian, Nerva, Trajan, als der Stifter des Provinzialcultus im narbonensischen Gallien betrachtet werden, da die Titel aller vier Herrscher mit den Worten imperator Caesar beginnen ${ }^{90}$ ).

Alibrandi hält freilich für unmöglich, unser Gesetz dem Traianus, geschweige dem Hadrianus, zuzuschreiben, und zwar deswegen, weil er dasselbe für cine lex rogata erklärt ${ }^{96}$ ). Doch ist diese letztere Behauptung sicher verfehlt, denn es unterliegt keinem Zweifel, daß die obige Urkunde eine lex data und nicht eine lex rogata ist. Da aber Alibrandi unzweifelhaft Recht hat, wenn er sagt: 'quanto rimane di questa legge spira una profonda renerazione per Augusto e pel culto di lui, ${ }^{97}$ ), was sich doch, wie er selbst hervorhebt ${ }^{98}$ ), mit der Annahme, daß dies ein von Augustus erlassenes Gesetz sei, schwerlich vereinigen läßt, so bleibt ihm offenbar nichts ibrig als anzuerkennen, daß das fragliche Gesetz eine lex data aus der nachaugusteischen Zeit ist.

Den Domitianus aber für den Urheber des Gesetzes zu halten, hindert denselben Gelehrten die Erwägung, daß es in der Lücke von Z. 13 für eine Lesung wie etwa: Caesar divi Vespasiani filus Domitianus Augustus u. s. w. noch weniger Raum giebt, als für die Ergänzung: Caesar Vespasianus Augustus u. s. w. ${ }^{99}$ ). Wir geben ihm das gerne zu, leugnen aber die Notliwendigkeit der Anfuihrung der Worte divi Vespasiani filius, deren Entbehrlichkeit u. A. aus mehreren Stellen der von Domitian erlassenen Gesetze von Salpensa und Malaca hervorgeht ${ }^{100}$ ). Lesen wir nun einfach:

empfunden wurde; man ziehe außerdem in Betracht eine nolanische Inschrift, in der wir einem curatori oper(um) publicor(um) dato a divo Aug(usio) Vespasian(o) begegnen (C. X 1266), vgl. dazu H. Schiller Gesch. der röm. Kaiserzeit I S. 572.

95) Es kommt hier also von allen Kaisern, deren Regierung in die obige Epoche $(69-98 \mathrm{n}$. Chr.) fällt, nur Titus nicht in Betracht, von dessen 'Titel wir schon oben gesprochen haben.

$\left.{ }^{96}\right)$ Bull. dell' Istit. di diritto rom. I p. 179: 'A Traiano e ad Adriano (trattandosi di una lex) non può pensarsi'. Die letzte kaiserliche lex rogata, die sich nachweisen läßt, gehört bekanntlich dem Nerva, vgl. Mommsen Staatsrecht $\mathrm{II}^{3}$ S. 883, O. Karlowa Röm. Rechtsgesch. I S. 624. Alibrandi vermuthet l. l. p. 193, daß das narbonensische Gesetz rom Consul des J. 12 n. Chr., C. Fonteius, dessen Vater einst Gallia Narbonensis verwaltet hatte, rogiert worden war.

97) Percii, fährt er fort, non posso credere che egli l'abbia dettata e proposta (Bull. dell' Istit. di diritto rom. I p. 192).

98) Vgl. oben Anm. 97.

${ }^{90)}$ Bull. dell' Istit. I p. 179.

${ }^{100}$ Vgl. z. B. Cap. 23 des salpensanischen Gesetzes (C. II 1963):

[ex] $h(a c)$ l(ege) exve edicto inp. Caes. Vesp(asiani) Aug(usti), imp(era-

Brought to you by | Université Paris Ouest Nanterre La Défense 
[Caesar Domitianus Augustus] u. s. w., so ist für diese Worte noch weniger ${ }^{101}$ ) Raum nöthig als für die formell zulässige ${ }^{102}$ ) Ergänzung: [Caesar Vespasianus Augustus] u. s. w.

Noch geringer als bei der letzten Lesung, und zwar um $2,3 \mathrm{Cm}$., wird die Gesammtlänge der ergänzten Stelle in Z. 13 sein, wenn wir das Gesetz dem Nerva zuschreiben und somit in der obigen Zeile imperator [Caesar Nerva Augustus] u. s. w. lesen. Denn das Wort Nerva $(2,4 \mathrm{Cm}$.), wodurch wir in diesem Falle das Wort Vespasianus $(4,7 \mathrm{Cm}$.) ersetzen, ist zweimal kürzer als das letztere.

Etwas anders verhält sich die Sache, wenn man die Herkunft des Gesetzes aus der traianischen Zeit annimmt und demgemäß in Z. 13 imperator [Caesar Nerva Traianus ${ }^{109}$ ) Augustus] u. s. w. liest. Bei dieser Lesung übersteigt die Gesammtlänge der Lückenergänzung $\left(19,4 \mathrm{bzw} .19,1 \mathrm{Cm}\right.$. $\left.{ }^{104}\right)$ selbst die maximale Länge der Lücke $(18 \mathrm{Cm}$.) um ein Bedeutendes, welcher Umstand uns den Grund abgiebt, die obige Annahme zu verwerfen ${ }^{105}$ ). Es läbt sich somit die Abfassungszeit des fraglichen Gesetzes noch enger begrenzen, und zwar ergiebt sich als der terminus ad quem der Entstehung desselben das 'Todesjahr Nerva's (98 n. Chr.).

Es entsteht nun die Frage, welcher von den drei Kaisern: Vespasian, Domitian, Nerva, - am wahrscheinlichsten für den Urheber des Gesetzes zu halten ist; wir ziehen aber vor, diese Frage etwas später zu erörtern, denn wir glauben dieselbe unten in einem anderen Zusammenhang mit größßerer Sicherheit entscheiden zu können.

\section{VIII.}

Nachdem wir nun einerseits die Widersprüche, zu welchen die übliche Altersbestimmung des narbonensischen Gesetzes noth-

toris)ve Tili Caes. Vespasian(i) Aug. aut imp. Cae(saris) Domitiani Aug(usti). Diese Stelle kann natürlich auch zur Widerlegung der ähnlichen, Vespasians Namen betreffenden Behauptung von Beurlier (s. oben Anm. 84) dienen.

101) Und zwar um $0,3 \mathrm{Cm}$, denn DOMIT ist $2,2 \mathrm{Cm}$. und VESPAS $-2,5 \mathrm{Cm}$. lang: die Breite der betreffenden Buchstaben auBer $0(0,3 \mathrm{Cm}$.) ist oben in Anm. 80, 81 und 83 angegeben.

102) Vgl. oben Cap. VI.

108) Es ist ja kaum zu bezweifeln, daß Trajans Name im officiellen Document, wovon die Rede ist, gerade so (Nerva Traianus), nicht aber bloß Traianus lauten mußte.

104) Die Länge der Ergänzung: [Caesar Nerva Augustus] u. s. w. ist von 15,7 bzw. 15,4 Cm.; schaltet man nun das Wort Traianus ein $(3,7 \mathrm{Cm}$.), so bekommt man für die Länge dieser neuen Ergänzung die im Texte soeben angegebenen Zahlen.

${ }^{105}$ ) Es würde aus demselben Grunde noch weniger müglich sein, Brought to you by | Université Paris Ouest Nanterre La Défense 
wendig führt, aufgedeckt, andererseits es nachgewiesen haben, daß in formeller Hinsicht nichts hindert, das Wort Vespasianus bzw. Domitianus oder Nerra in Z. 13 dieser Urkunde einzuschalten, bleibt uns noch übrig eine vorgefaßte Mcinung zu bestreiten, in Folge deren unsere Altersbestimmung des obigen Gesetzes wohl Manchem als paradox erscheint.

Es herrscht nämlich die Ansicht, daß der provinziale Kaisercultus überall schon in der frïhen Kaiserzeit eingefuihrt worden sci ${ }^{106}$ ). Dieses Vorurtheil hat wohl deshalb eine große Verbreitung gefunden, weil man bisher den Zusammenhang der Cultusgründungen mit den provinzialen Culturzuständen nicht ernstlich ins Auge faßste. Betrachtet man aber unter diesem Gesichtspunkte den Entwicklungsgang des uns beschäfligenden Instituts, so wird man leicht wahrnehmen, daß das Alter des Kaisercultus der einzelnen westlichen Provinzen und dasjenige der daselbst von den Römern eingepflanzten Cultur in umgekehrtem Verhältni $\beta$ zu einander stehn. Denn während der Kaisercultus in den am wenigsten romanisierten Provinzen des Westens bereits von den ersten Cäsaren gegründet wurde, ist die Einrichtung desselben in denjenigen Ländern, wo die römische Cultur schon in der frühen Kaiserzeit einheimisch war, auf eine längere Zeitcauer, die fast ein volles Jahrhundert erreicht, hinausgeschobin $\left.{ }^{10}\right)$. Die unten gegebene Zusammenstellung der betreffenden Thatsachen wird uns belehren, daß diese Unterscheidung mit einer Regelmäßigkeit durchgefuihrt wurde, die ein bewußtes politisches System der früheren Kaiser deutlich verräth. $\mathrm{Zu}$ nächst aber wollen wir, um die ausgesprochene Wahrnehmung von vorn herein innerlich $\mathrm{zu}$ begründen, die Frage aufwerfen, was wohl die Ursache dieser Politik gewesen sein mag. Es zeigt

den Hadrianus für den Urheber des fraglichen Gesetzes zu halten, denn die Lesung Traianus Hadrianus fordert noch mehr Raum als Nerva Traianus.

${ }^{106)}$ Vgl. Marquardt Ephem. epigr. I p. 213, V. Durny Comptes rendus de l'Acad. des sciences mor. et polit. N. S. XV (1881) p. 241, Brissaud in der franz. Bearbeitung des Mommsen-Marquardt'schen Handbuchs Bd. XIII S. 227, Willems Le droit public rom. ${ }^{5}$ S. 526 f., Beurlier Le culte imperial S. 19 , Boissier $L$ a religion rom. $I^{8}$ p. 150 . Wohl in Folge dieser Ansicht hat Beurlier für "plus simple" gehalten, das narbonensische Gesetz auf die augusteische Zeit als auf die des Vespasianus zu beziehen (s. oben Anm. 84).

107) Wir müssen dabei betonen, daß wir uns den Zusammenhang 2wischen dem Provinzialcultus und dem Provinziallandtag etwas anders denken als man es sonst zu thun pflegt: wir pflichten nämlich der Meinung bei, daß das Bestehen des Provinzialcultus immer dasjenige des Provinziallandtags voraussetzt, leugnen dagegen es entschieden, daß man umgekehrt von der Existenz des Letzteren stets auf diejenige des Ersteren schließen darf; vgl. darüber unten Cap. XII Brought to you by | Unniversite Paris Ouest Nanterre La Défense 
nun ein einfaches Raisonnement, daß zweierlei Momente - ein ethisch-psychologisehes und ein culturhistorisches - dabei maßgebend gewesen sein müssen: jenes betrift die Rolle der Kaiser bei Einfuihrung ihres eigenen Cultus, dieses liegt in der Bedeutung des letzteren, als eines der wirksamsten Factoren der Romanisierung.

Im Gegensatz zum municipalen Kaisercultus, dessen Linfiihrung kraft des Princips der municipalen Selbstverwaltung einzig und allein vom freien Ermessen der Gemeinden abling ${ }^{105}$ ), konnte der provinziale Cultus ohne directe Einmischung des Kaisers selbst nicht gegründet werden, da den Provinziallandtagen die gesetzliche Competenz dazu gänzlich fehlte ${ }^{109}$ ). So bot sich den Kaisern das Dilemma dar: entweder selbst als Begründer ihres Cultus aufzutreten, oder auf die Stiftung desselben überhaupt zu verzichten. Während die letztere Lösung der schwierigen Frage ihrem Interesse zuwider war, verbot ihnen sowohl die Rücksicht auf die öffentliche Meinung des römischen Bürgerthums und namentlich des oppositionell gesinnten Adels als ihr eigener 'Tact und ihr Sinn für Schicklichkeit, sich für die erstere zu entscheiden. Sie schlugen also den oben angedeuteten Mittelweg ein, indem sie die Sphäre des provinzialen Kajsereultus auf den der Romanisierung bedürftigen Theil des Reiches beschränkten, wo die civilisierende Kraft dieses Instituts ${ }^{110}$ ) das Anstößige ihres Verfahrens gewisser-

108) Thatsächlich kamen die Municipalen von Anfang an mit seltenem Eifer dem freilich nie offen ausgesprochenen, doch von Allen ja längst errathenen Wunsche der Herrscher entgegen. Betreffs der allgemeinen Verbreitung des Kaisercultus in den Provinzen schon bei Lebzeiten des Augustus vgl. Sueton. Aug. 59: provinciarum pleraeque super templa et aras ludos quoque quinquennales paene oppidatim constituerunt, auch Victor de Caess. 1,6. Wir mochten glauben, daß auch Italien in dieser Hinsicht nicht hinter den Provinzen zurückgeblieben ist, denn die von Hirschfeld Sitzungsber. S. 838 hervorgehobene Dürftigkeit der inschriftlichen Zeugnisse vom dortigen Augustuscultus ist doch wohl nur eine relative: man erinnere sich daran, daß überhaupt nur wenige Inschriften aus jener entfernten Epoche erhalten sind. Vgl. Tac. Ann. 1, 10 und Mommsen Staatsrecht II $^{3}$ S. 757 Anm. 1, auch Hermes XVII S. 641 Anm. 2.

109) Vgl. Guiraud Les assembl. provinc. S. $114 \mathrm{ff}$. und oben Cap. I.

$\left.{ }^{110}\right)$ Freilich dachte die Opposition davon etwas anders; vgl. Tac. Ann. 14, 31: qua contumelia et metu graviorum ... rapiunt arma .... acerrimo in veteranos odio. Quippe in coloniam Camulodunum recens deducti pellebant domibus, exturbabant agris, captivos, servos appellando ......Ad hoc templum divo Claudio constitutum (quasi arx aeternae dominationis aspiciebatur) delectique sacerdotes specie religionis omnis fortunas effundebant. Nec arduum videbatur excindere coloniam nullis munimentis saeptam, quod ducibus nostris parum provisum erat, dum amoenitati prius quam usui consulitur. In der von uns eingeklammerten Plirase erblicken wir eine ironische Bemerkung des Tacitus: sarkastisch

Brought to you by | Université Paris Ouest Nanterre La Défense 
maßen entschuldigte. Den iibrigen Provinzen des Westens wurde hingegen die kaiserliche Bewilligung, eigene Cultusstätten der neuen Religion zu errichten, trotz der darauf bezuiglichen Bitten der provinzialen Schmeichler, grundsätzlich vorenthalten ${ }^{111}$ ). In der That war selbst die Riicksicht auf die Förderung der römischen Cultur keine genuigende moralische Rechtfertigung der kaiserlichen $\mathrm{P}_{0}-$ litik in den Augen vicler Bürger: konnte doch Augustus nie iiber sich gewinnen, seinen Cultus selbst in den wildesten.Provinzen olme Verbindung mit dem Romacultus zu stiften ${ }^{112}$ ). Um so weniger mußte es denn den ersten Kaisern rïtllich erscheinen, göttliche Elıren zu genehmigen von Seiten derjenigen Provinzialen, die sich in ihrem Culturstande von den Italikern so gut wie durch nichts unterschieden ${ }^{113}$ ).

Anders war die Stellung der Kaiser in den letzten Decennien des ersten Jalırhunderts: der Kaisercultus war damals bereits so sehr mit den übrigen Reichsinstitutionen verwachsen, daß diese Herrscher keinen Anstand mehr zu nelımen brauchten, ihn iiberall, wo er noch felilte, einzurichten.

klingt auch der letzte Satz der citierten Stelle, in welchem eine Anspielung ebenfalls auf den Tempel des Claudius enthalten zu sein scheint.

111) Freilich mag Einer den Grund dieser Enthaltsamkeit der Kaiser in Bezug auf die romanisierteren Provinzen vielmehr darin erblicken, daß dieselben zugleich Senatsprovinzen waren, während die wenig romanisierten Länder zur Zahl der kaiserlichen Provinzen gehörten; doch ist es ja lockannt, wie wenig sogar die ersten Kaiser daran Anstand nahmen, aus ibrem Rechte, specielle Regulative auch für die Senatsprovinzen zu erlassen, vollen Gebrauch zu machen (vgl. Mommsen Staatsrecht $\mathrm{II}^{3} \mathrm{~S} .859$ f.).

$\left.{ }^{112}\right)$ Der Umstand, daß Augustus nicht sich allein vergöttern ließ, zeugt wohl davon, daß er die Anstößigkeit des neuen Cultus womöglich zu vermindern suchte; die Wahl aber der Göttin Roma zu seiner Gefährtin erklärt sich am wahrscheinlichsten aus der Bestimmung des obigen Cultus, den Zwecken der Romanisierung zu dienen. Charakteristisch ist die von Dio (s. oben Anm. 20) berichtete Thatsache, daß Augustus die zu Ehren desselben und der Göttin Roma errichteten Provinzialtempel zu Pergamon und Nikomedia ausschließlich für die griechische Bevölkerung der betreffenden Provinzen bestimmt hat, während die für den Gebrauch der römischen Bürger bestimmten Kaisertempel derselben Provinzen zu Ephesos und Nikaea der Göttin Roma und dem divus Iulius gewidmet waren. Man ersieht hieraus, daß selbst der gemeinschaftliche Cultus der Göttin Roma und des Augustus dem Letzteren wenigstens in seiner ersten Regierungsperiode anstößig schien, wann es sich um die Heranziehung der römischen Bürger zur Theilnalıme am Kaisercultus handelte.

${ }^{113}$ ) Vgl. die unten (Cap. XII u. XV am Anf., und Anm. 130) angeführten Stellen von Strabo $(3,2,15)$ über Baetica's Culturzustände, von Plinius dem Aelteren (N. H. 3, 31) über diejenigen des narbonensischen Galliens, von Plinius dem Jüngeren $(e p .2,11,19)$ und von Tacitus (Ann. 2, 50) über Africa.

Brought to you by $\mid$ Universite Paris Ouest Nanterre La Défense 
IX.

Von diesen allgemeinen Vorbemerkungen wenden wir uns zur Betrachtung der Thatsachen, welchen die von uns behauptete Abhängigkeit der Cultusgründungen von den provinzialen Culturzuständen hervorgeht.

Zur Vertheidigung unseres Satzes von der frühen Einführung des Kaisercultus in den wenig romanisierten westlichen Provinzen brauchen wir wohl mit Niemandem eine Lanze zu brechen: es genügt die allbekannten Nachrichten über die Anfänge des obigen Cultus in diesen Provinzen aufzuzählen.

So ward, um nur sicher bezeugte Beispiele anzuführen, der provinziale Kaisercultus schon im J. 12 v. Chr. in den Tres Galliae eingerichtet ${ }^{114}$ ). Dann wurde die Ara Ubiorum am Niederrhein, noch vor dem Jahre $9 \mathrm{n}$. Chr. ${ }^{115}$ ), wohl bald nach der Eroberung des rechten Rheinufers, gegrïndet ${ }^{116}$ ). Unter Tiberius entstand der Provinzialcultus im tarraconensischen Spanien und in Lusitanien ${ }^{137}$ ). Unter Claudius ward sein Tempel zu Camulodunum, wahrscheinlich unmittelbar nach der Besitzergreifung Britanniens errichtet, wohl um als Mittelpunkt des britannischen Provinzialcultus zu dienen ${ }^{118}$ ).

Wenn die soeben angeführten frühen Cultuseinrichtungen durch die Rücksicht auf die Romanisierung der betreffenden Länder bedingt wurden, so konnte dieser Gesichtspunkt für die griechischen Provinzen natürlich keine Geltung haben. Finden wir nun aber den Kaisercultus in diesen Provinzen noch früher als in den wenig romanisierten westlichen eingeführt, so erklärt sich diese Erscheinung schlechterdings nur dadurch, daß die im Orient längst einheimische Vergötterung der Herrscher im Verlauf der Zeit zu einem wahren BedürfniB der dortigen Bevölkerung geworden war ${ }^{119}$ ), weßhalb selbst Tiberius keinen Anstand daran nahm, die ihm von den Griechen angebotenen göttlichen Ehren zu genehmigen ${ }^{120}$ ). Nicht ohne Einfluß auf diese Entwickelung ist wohl auch der Umstand geblieben, daß

14) Vgl, oben Anm. 11.

115) Vgl, Tac. Ann. 1, 57.

116) Vgl. Bergk Zur Gesch. u. Topogr. d. Rheinl. S. 140, Hirschfeld Sitzungsber. S. 841.

137) Darüber handeln wir unten in Cap. XI.

118) Vgl. Hirschfeld Sitzungsber. S. 841.

119) Vgl. hierüber Hirschfeld 1. 1. S. 833 ff., Guiraud Les assembl. provinc. S. 15 ff., Beurlier S. 2 ff., Mommsen Staatsrecht II $^{8}$ S. 756.

120) Tac. Ann. 4, 15 (zum J. 23): decrevere Asiae urbes templum Tiberio matrique eius ac senatui; et permissum statuere.

Brought to you by |UniversitéParis Ouest Nanterre La. Défense 
die Römer nur einen ganz kleinen Theil der Bevölkerung dieser Länder bildeten.

$\mathrm{X}$.

Der andere oben aufgestellte Satz, daß eine größere Entwickelung der römischen Cultur stets eine um so spätere Einrichtung des Kaisercultus in der betreffenden Provinz zur Folge hatte, wird zunächst durch die späte Einführung dieses Cultus in der Provinz Africa bestätigt.

Eine furnitanische, aus der Regierungszeit des Commodus stammende Inschrift, die P. Mummio L. f. Papir. Saturnino sac(erdoti) p(rovinciae) A(fricae) a(nni) CXIII, dec(urioni), II vi[ra]l(i) municip(ii) Furnitani, cui cum ordo honorem flíamonii) obtulisset, pron(aum) cum ornament(is) temp(li) Merc(uriv) [ob] excusation(em) honor(is) . . . . [ [ feci]t ${ }^{121}$ ) gewidmet ist, legt das Zeugniß ab, daß der Provinzialcultus von Africa erst etwa von Vespasian gegründet worden ist ${ }^{122}$ ). Zwar nimmt Hirschfeld an, sich an eine von Cagnat ausgesprochene Vermuthung ${ }^{123}$ ) anschließend, daß Vespasian das von ihm vorgefundene Institut nur

181) C. VIII suppl. 12039.

122) Es ergiebt sich aus drei anderen furnitanischen Inschriften (C. VIII suppl. 12028-12030), daß Saturninus den Pronaos während des vierten Consulats des Commodus, also in der Zeit zwischen dem Jahre 183 und dem Jahre 185, dediciert hat. Mit Rücksicht darauf nimmt man an, daß auch die oben angeführte Inschrift des Saturninus, welche von der Errichtung einer Bildsäule zu Ehren desselben zeugt, aus den Jahren 183-185 stammt, und stellt mit Hülfe einer einfachen Berechnung fest, daß die Gründung des africanischen Provinzialcultus in die Periode vom J. 71 bis zum J. 73 n. Chr. fällt (s. Joh. Schmidt's Anm. zu C. VIII suppl. 12039, vgl, auch Cagnat Archiv. des miss. scientif. et litt. 3 sér. XIV p. 24 ; die von Guiraud Les assembl. prov. S. 78 vorgeschlagene Erklärung der Worte anni CXIII ist schon von Hirschfeld Sitzungsber. S. 841 Anm. 38 mit Recht abgewiesen worden). Dieses Ergebniß aber ist außer jener Annahme noch durch eine andere bedingt, nämlich daß Saturninus in eben demselben Jahre das Provinzialpriestertlum bekleidete, in welchem seine Statue errichtet wurde. Wohl ist dies Alles möglich, sicher ist es jedoch nicht; darum ziehen wir es vor, auf die genaue Feststellung des Jahres der Cultusgründung in Africa zu verzichten. Man kann übrigens beinahe sicher behaupten, daß nur wenige Jahre zwischen der Bekleidung des Provinzialpriesterthums durch Saturninus und der Aufstellung seiner Bildsäule bzw. Einweihung des Pronaos verflossen sind.

128) Archives des miss. scientif. et littér. 3 sér. XIV (Paris 1888) p. 24 sq.: 'Le texte d'Henchir Boudja [d. h. C. VIII suppl. 12039] tendrait à prouver que Vespasien fut le créateur ou au moins le réorganisateur du concilium provinciae. Les documents que nous possédons sur ce dernier sont encore trop peu nombreux pour nous apporter des arguments pour ou contre une telle conclusion'.

Brought to you by |Université Paris Ouest Nanterre La Défense 
reorganisiert habe ${ }^{124}$ ), doch enthält der Wortlaut sowohl der soeben angefïhrten als anderer verwandten Inschriften ${ }^{1 \% 5}$ ) keine Hindeutung auf diese vermeintliche Reform. Wohl sucht derselbe Gelehrte, seine Ansicht dadurch einigermaßen zu vertheidigen, daß er auf die Analogie Numidiens hinweist, wo nach ihm ein flamen provinciae bereits vor Vespasian fungiert zu haben scheint ${ }^{126}$ ). Aber einerseits ist das Alter der cirtensischen Inschrift ${ }^{127}$ ), auf die Hirschfeld sich beruft, zu unbestimmt, um Folgerungen iiber die Zeit der Einfuihrung des Provinzialcultus in Numidien zu gestatten ${ }^{128}$ ); andererseits ist der Schluß von Numidiens Verhältnissen auf diejenigen der Provinz Africa noch keineswegs berechtigt ${ }^{129}$ ), selbst wenn wir es als eine unbestreitbare Thatsache anerkennen, daß es einen gemeinsamen Kaisercultus von ganz Numidien schon vor Vespasianus gegeben habe.

Nichts steht also der Annahme im Wege, daß gerade die Einfiihrung und nicht die Reorganisation des africanischen Pro-

124) Sitzungsber. S. 841

125) Vgl. besonders die folgende Inschrift aus Simitthus, C. VIII suppl. 1461 1: C. Otidio P. f. Quir. Iovino praefecto fabrum, sacerdoti provinc. Afric. anni XXXVIII, qui primus ex colonia sua hunc honorem gessit.

126) Sitzungsber. S. 841 Anm. 38.

127) C. VIII 7987: Dis Manib(us) Caeciliae Nigellinae Caecili Galli flamin(is) provinciae filiae.

${ }^{1 \times 8}$ ) Es steht nämlich nur das fest, daß diese Inschrift nicht vor Gaius' Regierung eingehauen worden sein kann, wie die Erwähnung der quinque decuriae in der noch bei Nigellina's Lebzeiten abgefaßten Inschrift des Caecilius Gallus (C. VIII 7986) dies zeigt. Mommsen (im Hermes I S. 60) und Hirschfeld (Annali dell' Instit. di corrisp. archeol. 1866 p. 76, vgl. auch Sitzungsber. Anm. 38 u. 76) schreiben die beiden obigen Inschriften dem ersten Jahrhunderte zu, und diese Zeitbestimmung ist viel wahrscheinlicher als diejenige von Cl. Pallu de Lessert (Etudes sur le droit public et l'organis. sociale de l'Afr. rom.: Les assembl. prov. et le culte prov. dans l'Afr. rom. Paris 1884 p. 64), der es vorzieht, wenigstens Nigellina's Grabschrift etwa in die Regierungszeit des Severus zu versetzen, da Numidien, dessen Priester unter flamen provinciae zu verstehen ist (vgl. dazu Hirschfeld Annali 1866 p. 75, Sitzungsber. S. $850 \mathrm{Anm}$. 76; Pallu de Lessert S. 63), erst unter Severus zur eigentlichen Provinz geworden ist (Marquardt Rom. Staatsverw. I ${ }^{2}$ S. 470). Doch hat schon Hirschfeld (Annali a. a. 0.) wahrscheinlich gemacht, daß der Priester des numidischen Kaisercultus den gleichsam technisch gewordenen Titel flamen provinciae bereits seit dem ersten Jahrhundert führen konnte; man vergleiche dazu eine zu Henschir Dermulîa aufgefundene Inschrift (C. VIII suppl. 14882), die wohl so zu lesen ist: [e]x au[c(toritate)] imp[erator(is) Ve]spasian(i) [Cae$s$ (aris)] Aug(usti) p(atris) p(atriae) fine[s] provinci(ae) $A[$ fric(ae)] nova[e] $e[t] \operatorname{vet}[\operatorname{er}(i s)] \operatorname{der}[$ ecti], oder - was auf die überlieferten Züge noch besser paBt - fine[s] provincial[es] Nov(ae) $A[f] r(i c a e) e[t] \operatorname{Vet}[\operatorname{er}(i s)]$ $\operatorname{der}[$ ecti] .

${ }^{129}$ ) Vgl. unten Cap. XV.

Brought to you by |Úniversité Paris Ouest Nanterre La Défense 
vinzialcultus dem Vespasianus zuzuschreiben ist. Es war aber Africa bekanntlich eine der ältesten und sicherlich auch der romanisiertesten Provinzen des Westens ${ }^{190}$ ).

\section{XI.}

Noch belehrender sind die Daten der Cultuseinfiilhung in denjenigen Provinzen, die zu geographischen Complexen verbunden waren, ohne doch auf der gleichen Culturstufe zu stehen. Man wird sich nämlich bei ihrer Beobachtung davon überzeugen, daß die ersten Kaiser bei der Gründung ihres Cultus selbst innerhalb jener Complexe die oben behauptete Unterscheidung zwischen romanisierteren und wenig romanisierten Provinzen machten, trotz der geographischen Nähe und der ethnographischen Verwandtschaft ihrer Bevölkerungen.

So finden wir, daß auf der iberischen Halbinsel die von der römischen Cultur verhältnißmäßig noch wenig berührten Lusitanien und Hispania Tarraconensis den Provinzialcultus spätestens unter Tiberius erhielten, während derselbe Cultus im durch und durch romanisierten Baetica erst etwa zur Zeit des Vespasianus eingeführt wurde.

Was nun das tarraconensische Spanien anbelangt, so pllegt man wohl mit Recht als das Jahr der Einrichtung des Kaisercultus in dieser Provinz das Jahr 1 ${ }^{2} \mathrm{n}$. Chr. anzusetzen ${ }^{131}$ ), nämlich mit Riicksicht auf die oben besprochene Stelle des Tacitus ${ }^{13 y}$ ).

130) Vgl. Tac. Ann. 2, 50 adultero Manlio Italia atque Africa interdictum est; Plin. ep. 2, 11, 19 Mario urbe Italiaque interdicendum, Marciano hoc amplius Africa, und überhaupt Mommsen $R$. $G$. V S. 647 f., Jung, Die roman. Landschaften des röm. Reiches S. 119 ff., Marquardt Rüm. Staatsverw. I ${ }^{2}$ S. 474.

191) Vgl. Marquardt Eph. epigr. I p. 200, Röm. Staatsverw. I ${ }^{2}$ p. 510, Guiraud Les assembl. prov. p. 48. 56, Hirschfeld Sitzungsber. p. 840.

132) Ann. 1, 78 (s. oben Cap. I). Beiläufig zu bemerken, scheint diese Auffassung der taciteischen Stelle in Widerspruch zu stehen mit der üblichen Annahme, daß das Bestehen eines Provinziallandtags stets dasjenige des Provinzialcultus voraussetze (vgl. oben Anm. 107). Denn, hat die spanische Gesandtschaft den Tiberius im J. 15 wirklich im Namen der ganzen Provinz um die Cultusgründung ersucht, so liegt es auf der Hand, daß vor dem J. 15 n. Chr. noch kein Provinzialcultus und doch schon eine Art Provinziallandtag daselbst existiert hatte. Wenigstens ist die Vermuthung, daß die Anfänge des Kaisercultus von Hispania Tarraconensis bis auf die Zeit der Errichtung des bekannten Augustusaltars zu Tarraco (Quintil. 6, 3, 77; vgl. Cohen Medailles imperiales $I^{2}$ S. 158 n. 726) zurückreichen (vgl. Hübner Röm. Herrschaft in Westeuropa S. 196), kaum als wahrscheinlich zu bezeichnen. Der scheinbare Widerspruch, den Jemand vielleicht erblicken würde zwischen der häufig vorkommenden Titulatur der tarraconensischen Provinzialpriester: flamen Brought to you by | Université Paris Ouest Nanterre La Défense 
Daß auch in Lusitanien der Provinzialcultus ziemlich früh eingeführt worden ist, dies bezeugt eine unzweifelhaft der frühen Kaiserzeit angehörige emeritensische Inschrift, C. II 473: Divo Augusto Albinus Albini f(ilius) flamen divi Aug(usti) provinciae ${ }^{133}$ ) Lusitaniae. Zwar befremdet dieselbe durch den sonderbaren Namen des Priesters, doch läßt sich diese Eigenthümlichkeit vielleicht einfach dadurch erklären, daß der auf dem Gebiete der römischen

Rom a e, Divorum et Augustorum (C. Il 4205. 4222. 4228. 4235 u. s. w.) und der Thatsache, daß der Provinzialtempel in Tarraco zu Ehren des divus Augustus allein errichtet wurde (s. oben Cap. I), kann wohl bequem durch die Annahme beseitigt werden, daß die Anknüpfung des Romacultus an den provinzialen Kaisercultus des tarraconensischen Spaniens erst aus der Zeit des Hadrianus datiert, wo der Romacultus bekanntlich von Neuem Aufschwung genommen hat (vgl. Preller $\boldsymbol{R} . \boldsymbol{M}$. II $^{8} \mathrm{~S}$. 357 und unsere Diss. $\$ 40 \mathrm{~S}$. 35 f.). Es ist zu beachten, daß die älteste der datierbaren Inschriften, in denen der obige Titel vorkommt, der nachhadrianischen Zeit angehört (C. II 4249). Als äußerer $A n l a ß$ zur Verknüpfung des Cultus der Göttin Roma mit dem des Augustus mag die Wiederherstellung des tarraconensischen Tempels des Letzteren durch Hadrianus (vgl. oben Anm. 22) gedient haben.

188) Genau so - und nicht abgekürzt prov(inciae), wie dies aus Hübner's Anmerkung im Corpus über die Gleichartigkeit der Copien von Bourdelot und Morales zu schließen ist - ist dieses Wort im Bourdelot'schen Codex angegeben, den ich selbst verglichen habe (cod. Vatic. Regin. 949 f. $79^{\prime}$ : ' $m$ i fu mostrata anco questa inscrittione dedicata ad Augusto'). Man muß beachten, daß auch die Vertreter der älteren Ueberlieferung, Mameranus und Strada, provinciae ebenfalls ausgeschrieben angeben. Uebrigens glaube ich, daß man bei Lesung dieser Inschrift auch sonst eben von der älteren Ueberlieferung derselben ausgehen muß, da die beiden jüngeren Gewährsmänner überhaupt zum Interpolieren geneigt zu sein scheinen, wie eine Vergleichung ihrer Copien einer braccaraugustanischen Inschrift mit dem Original es zeigt. Es steht nämlich im Bourdelot'schen Codex, dessen Varianten mit denjenigen der Copie von Morales genau ubereinstimmen, die obige Inschrift (C. II 2416) folgendermaßen überliefert: Isidi Aug. sacrum $\|$ Lucretia Fida sacerd. perp. Rom. \|l et Augg. conventus Braccarae $\|$ Aug. d. (fol. 130' mit der Bemerkung: 'in un altro sasso cosi si legge', die eine unmittelbare Bekanntschaft Bourdelot's mit dem Original vorauszusetzen gestattet), während Hübner's Copie derselben Inschrift das Folgende angiebt: 'Isidi Aug. sacrum || Lucretia Fida sacerd. perp. \| Rom. et Aug. \| conventuus Bracaraug. $d$. Was nun die emeritensische Inschrift (C. II 473) anbetrifft, so möchten wir auf Grund der Copien von Mameranus (ALBINVS ALBVI - FEL - AMERI DIVAE AVG PROVINCIAE LVSITAN) und von Strada (ALBINVS $\cdot A \mathrm{LB} \cdot \mathrm{V} \cdot \mathrm{I} \cdot \mathbf{E} \cdot$ AMEN DIVAE AVG PROVINCIAE LVSITA) für dieselbe von $Z .2$ an etwa die Lesung ALBINVS - AL $3 N I$ (bzw. ALBNI) - F · FLAMEN · DIV · AVG - PROVINCIAE - LVSITAN oder ALBINVS - ALBVI - FEL · flAMEN u. s. w. vorschlagen. Bei der letzteren Lesung, welche den von Mameranus überlieferten Zügen sehr nahe kommt, erhält einerseits der Name des Vaters von Albinus einen ganz barbarischen Charakter, andererseits bekommt die Inschrift selbst durch die Form feil(ius) ein al terthïmlicheres Gepräge

Brought to you by 
Gebräuche noch wenig bewanderte Neubürger, statt seines vollständigen Namens, der etwa C. Iulius Albini (bzw. Albui) f. Albinus lautete, die gewöhnlichere abgekürzte Form desselben auf den Stein eingraben ließ.

Schließt man aber andererseits mit Hirschfeld ${ }^{134}$ ) nach dem Namen des Albinus, daß der Letztere nicht römischer Bürger gewesen sei, was wohl mit der sonst iblichen und durch zahlreiche Inschriften bezeugten Praxis der westlichen Provinzen ${ }^{135}$ ) in directem Widerspruch stehen würde, so bleibt nichts übrig als anzunehmen, daß in wenig romanisierten westlichen Provinzen, wie Lusitanien, das Priesterthum des Provinzialcultus, wenigstens in der ersten Zeit nach der Gründnng des Letzteren, nicht, wie dies später im römischen Westen wohl ïberall die Regel war, ausschließlich von römischen Bürgern bekleidet zu werden pflegte, sondern mitunter auch umgekehrt das römische Bürgerrecht durch die Bekleidung des Provinzialpriesterthums erlangt wurde ${ }^{136}$ ).

Als Belege für die ziemlich frühe Einführung des provinzialen Kaisercultus in Lusitanien mögen noch die folgenden, etwa aus der claudischen Zeit stammenden ${ }^{197}$ ) Inschriften dienen: C. II $35 L$. Cornelio C. f. Boccho flam. provin(ciae), tr.(ibuno) mil. colonia Scalabitana, und C. II suppl. 5184: . . [C]ornelio $L$. (oder vielleicht C.) f. $[B]$ occho [flamin]i provinc., [tr.] mil. [l]e[g.] III Aug(ustae), welche beide wahrscheinlich dieselbe Persönlichkeit nennen $\left.{ }^{138}\right)$.

\section{XII.}

Viel später scheint der Kaisercultus in der Provinz Baetica eingefiihrt worden zu sein, über deren Culturzustand uns Strabo

134) Sitzungsber. S. 851 Anm. 82, vgl. auch S. 849 Anm. 71.

$\left.{ }^{135}\right)$ Vgl. Hirschfeld Sitzungsber. S. 851.

196) Ist dem so, so kommt eine andere Aehnlichkeit zwischen dem Kaisercultus der wenig romanisierten westlichen und dem der griechischen Provinzen zu Tage, da in den; Letzteren der Besitz des römischen Bürgerrechts nicht die nothweudige Bedingung zur Erreichung der Priesterwürde war (vgl. Ilirschfeld Sitzungsber. S. 85l). Betreffs der früher angedeuteten Aehnlichkeit vgl. oben Cap. IX.

187) Vgl. Hübner zu C. II suppl. 5184 und Teuffel-Schwabe Gesch. d. röm. Lit. ${ }^{5}$ \& 291,6 S. 709 .

188) Vgl. endlich die conimbricensische Inschrift C. II $41^{*}$, die Hübner m. E. ohne genügenden Grund für unecht erklärt hat (er glaubt nämlich, daß̧ dieselbe von einem Fälscher der oben angeführten Inschrift des Albinus C. II 473 nachgebildet worden ist). Mir scheint dieselbe, echt zu sein, nur ist sie offenbar am Ende interpoliert, denn sowohl die überlieferte Schlußformel als das Fehlen einer Ortsbestimmung bei dem Priestertitel sind auf einem derartigen Denkmal befremdend. Im Original mag Folgendes gestanden haben: Divo Au- 
$(3,2,15)$ die folgende beredte Auskunft giebt: of $\mu \varepsilon ́ v i o c$ Toup-

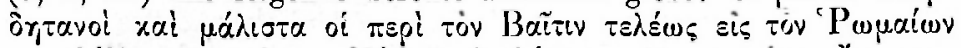

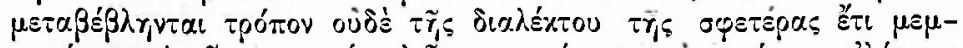

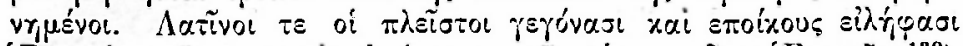

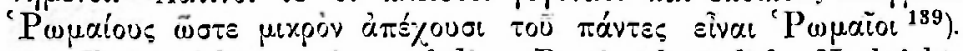

Zwar giebt es eine auf diese Provinz bezügliche Nachricht, aus welcher wohl Manche schließen, es sei der provinziale Kaisercultus daselbst spätestens unter Tiberius gegründet worden, doch erweist sich diese Folgerung nach einer genaneren Priifung als ganz unhaltbar. Es berichtet nämlich Tacitus unter dem J. 25: per idem tempus Hispania ulterior missis ad senatum legatis oravit, ut exemplo Asiae delubrum Tiberio matrique eius exstrueret ${ }^{140}$ ). Man kann wohl aus dieser Erwähnung der baetischen Gesandtschaft auf das Bestehen eines concilium provinciae Baeticae schließen. Zieht man aber hieraus die weitere Folgerung, daß das Bestehen des baetischen Provinziallandtags beweise, es sei auch ein provinzialer Kaisercultus in Baetica unter Tiberius dagewesen, so ist dieselbe als eine völlig unbegründete abzuweisen. Denn wäre die Einrichtung der Provinziallandtage wirklich von der Cultusgründung so unbedingt abhängig, wie man es zu glauben pflegt, so würde man annelmen miissen, daß beispielsweise in Africa der Provinziallandtag erst von Vespasianus eingerichtet worden, sei ${ }^{141}$ ), d. h., mit anderen Worten, annehmen, daß einer der ältesten und romanisiertesten Provinzen die Wohlthaten dieser Institution von den Kaisern fast ein volles Jahrhundert hindurch versagt wurden, während selbst wenig romanisierte Länder vom Beginn der Kaiserzeit an ihre Landtage hatten. Das würde ja eine schreiende Ungerechtigkeit namentlich der in Africa ansässigen römischen Bürgerschaft gegenüber gewesen sein.

Wir behaupten dagegen, eben mit Rücksicht auf dje späte Einführung des provinzialen Kaisercultus in Africa, daß dieser Cultus nicht immer gleichzeitig mit der Einirichtung der betreffenden Provinziallandtage gegründet wurde ${ }^{142}$ ), und daß u. A. auch

gusto L. Papirius L. f. flamen Augustalis PRO . . INC • LV . . ITAII . . . , d. h. pro[v]inc(iae) $L u[s]$ ita $[$ niae $]$, woraus Britto bzw. sein Gewährsmann 'pro salute et incolumitate civium' machte.

189) Vgl. auch Plin. N.H. 3,7 und im Allgemeinen Mommsen $R . G$. $\checkmark$ S. 62, Jung Dic roman. Landschaften S. 14.19.

$\left.{ }^{140}\right)$ Ann. 4, 37.

14t) Gerade das nimmt Joh. Schmidt an, indem er aus der Inschrift des Saturninus C. VIII suppl. 12039 (vgl. oben Cap. X) so folgert: 'cadit igitur sacerdotii ne c non concilii provinciae Africae origo intra annos fere $71-73^{\prime}$.

${ }^{142}$ ) Vgl. oben Anm. 107, wo wir unsere Ansicht über den Zusammenhang zwischen der Cultus- und der Landtagsgründung präciser formuliert haben.

Brought to you by | Université Paris Ouest Nanterre La Défense 
die Provinz Africa ihr concilium schon längst vor Vespasians Zeit, d. h. vor der Cultusgrïndung gehabt hatte ${ }^{\mathbf{1 4 3}}$ ).

Es beweist also der obige Bericht des Tacitus keineswegs das Bestehen des baetischen Provinzialcultus unter Tiberius ${ }^{144}$ ). Im Gegentheil, es führt uns eine eingehendere Prüfung der fraglichen Stelle zu dem Schlusse, daß Baetica damals aller Wahrscheinlichkeit nach noch keinen Kaisercultus hatte. Wäre nämlich der Letztere daselbst wirklich bereits vor dem Jahre 25 eingeführt worden, so würde olne Zweifel auch ein Augustustempel etwa zu Corduba schon damals existiert haben, und Tiberius würde dann in der Rede, durch welche er seine Ablehnung des Gesuchs von Baetica zu motivieren suchte ${ }^{145}$ ), gewiB nicht unterlassen haben, auch diesen Umstand hervorzuheben oder wenigstens desselben Erwähnung zu thun ${ }^{146}$ ). Da aber er einen baetischen Provinzialtempel mit keinem Worte angedentet hat, so ist hieraus wohl am natïrlichsten zu schließen, daß noch kein solcher damals in Baetica vorhanden war ${ }^{147}$ ). Man ziehe außerdem in Betracht, daß Tacitus, der sonst ïber alle wichtigeren Provinzialgesandtschaften

143) Vgl. Sueton. Tib. 31 : tanta consulum auctoritate, ut legati ex Africa adierint eos querentes trahi se a Caesare, ad quem missi forent, wo unter legati ex Africa vielleicht eine africanische Provinzialgesandtschaft gemeint ist.

144) Ebenso wenig kann man aus einer anderen taciteischen Stelle, Ann. 14, 28 (zum J. 60): fine anni Vibius Secundus eques Romanus accusantibus Mauris repetundarum damnatur, schließen, daß Mauretanien damals den Provinzialcultus hatte. Ja man darf dieselbe nicht einmal dafür als sicheres Zeugniß anführen, daß es im Jahre 60 schon einen mauretanischen Provinziallandtag gegeben habe, wie es Guiraud thut (Les assembl. provinc. S. 174). Denn es ist möglich, unter Mauris nicht die vom concilium erwählten Repräsentanten cler ganzen Provinz, sondern Vertreter irgend einer oder mehrerer einzelnen mauretanischen Gemeinden bzw. Privatpersonen zu verstehen; vgl. Plin. ep. 2, 11, 2 Marius Priscus accusantibus Afris, quibus pro consule praefuit, omissa defensione iudices petiit. ego et Cornelius Tacitus adesse provincialibus iussi etc. und ep. 3, 9, 4 Marium una civitas publice multique privati reum peregerunt, in Classicum tota provincia incubuit.

$\left.{ }^{145}\right)$ Tac. Ann. 4, 37-38. Vgl. Hirschfeld Sitzungsber. S. 842 Anm. 43.

146) Wie man denn in Rom bei Entscheidung des Streites der asiatischen Städte um die Ehre, einen Tempel des Tiberius zu errichten, den Ansprüchen der Pergamener entgegenhielt, daß sie schon einen Tempel der Göttin Roma und des divus Augustus besitzen, vgl. Tac. Ann. 4, 55 (oben in Anm. 20).

147) Vgl. auch Hirschfeld Sitzungsber. S. 849 nebst Anm. 73. Es lohnt sich außerdem zu bemerken, daß von den uns erhaltenen cordubensischen Münzen des Augustus und des Tiberius keine einzige einen Kaisertempel erwähnt (vgl. Cohen Med. imper. I ${ }^{2}$ p. 150 n. 606.608-610; Heiß Descr. gener. des monn. antiq. de l'Espagne Paris 1870 p. 298 n. 7-10, Taf. XLII), während man Abbildungen der Tempel des divus Augustus sowohl auf emeritensischen als auf tarraconensischen Münzen findet (Cohen $\mathrm{I}^{2}$ p. 149 n. 585. 586; p. 158 n. 727, vgl, auch n. 726). 
Bericht erstattet, nirgends erwiihnt, daß Baetica auch schon vor dem .Jahre $2 \check{5}$ Tiberius um die Cultusgründung einmal gebeten habe ${ }^{148}$ ). Diesen Cultus aber als bereits unter Augustus eingeführt vorauszusetzen ist, auch abgesehen von der Nichterwikhnung eines baetischen Kaisertempels in der obigen Rede des Tiberius ${ }^{149}$ ), aus dem Grunde unmöglich, weil der crste Priester von Baetica, nach der Angabe einer gleich unten zu besprechenden Inschrift, einfach flamen Augustalis und nicht sacerdos (bzw. flamen) Romae et Augusti ${ }^{150}$ ) hieß, womit auch der Umstand gut iibereinstimmt, da $B$ der Cultus der Göttin Roma in keinem uns erhaltenen 'Titel der späteren baetischen Provinzialpriester angedeutet wird ${ }^{151}$ ).

\section{XIII.}

Schreiten wir nun von den schriftstellerischen zu den inschriftlichen Zeugnissen für den baetischen Provinzialcultus fort, so finden wir eine castulonensische Inschrift, die allem Anschein nach

148) Wir wollen jedoch damit keineswegs sagen, daß solche Gesandtschaften von Baetica (sowie von Africa oder vou Gallia Narbonensis) nicht einmal bcabsichtigt wurden, denn eine derartige Behauptung würde ja in vollem Widerspruch mit der allbekannten Schmeichelei der Provinzialen stehen. Wohl aber können wir vermuthen, daß diese beabsichtigten Legationen in der frühen Kaiserzeit deshalb nicht zur Ausführung gelangten, weil die vorläufigen Gesuche um die Erlaubniß die betreffende Gesandtschaft abzuordnen durch die Kaiser schlechterdings abgelehnt zu werden pflegten : denn es ist ja kaum zu bezweifeln, daß die Provinziallandtage wenigstens in den Fällen, wo es sich um solche den Kaiser persönlich angehende, gewissermaßen heiklige Dinge handelte, keine Deputation an denselben ohne seine ausdrückliche Bewilligung dazu senden durften. Wenn aber der baetische Landtag nicht seine Absicht aufgab, eine Gesandtschaft im J. 25 an Tiberius zu schicken, obgleich es von vorn herein bekannt war, daß sie erfolglos sein sollte, so geschah dies vermuthlich auf Wunsch des Kaisers selbst, der specielle Gründe dafür hatte, welche bei Tacitus Ann. 4, 37 dargelegt sind: qua occasione Caesar validus alioqui spernendis honoribus et respondendum ratus iis, quorum rumore arguebatur in ambitionem flexisse, huiuscemodi orationem coepit: 'Scio, patres conscripti, constantiam meam a plerisque desideratam, quod Asiae civitatibus nuper idem istud petentibus non sim adversatus. Ergo et prioris silentii defensionem et quid in futurum statuerim simul aperiam' $\mathrm{u}$. $\mathrm{s}$. w.

${ }^{149}$ ) Dadurch, daß es sich hier um eine der romanisiertesten Provinzen handelt, erklärt sich der sonst unbegreifliche Umstand, daß Tiberius das Gesuch des baetischen Landtags bloß abgelehnt, nicht aber dem Letzteren einen Tempel etwa zu Ehren des divus Augustus zu errichten vorgeschlagen hat: er hielt offenbar die Einführung des provinzialen Kaisercultus in Baetica überhaupt für nicht zeitgemäß.

$\left.{ }^{150}\right)$ Vgl. dazu oben Cap. III.

151) Es lautet nämlich der vollständige Titel dieser Priester in den bisher zum Vorschein gekommenen Inschriften stets flamen Divorum Augustorum provinciae Baeticae (C. II 2221. 2224 u. a.).

Brought to you by | Université Paris Ouest Nanterre Là Défense 
den ersten Priester von Baetica erwähnt und deswegen trotz ihrer Verstümmelung und ihrer mangelhaften Ueberlieferung sowie einer gewissen Unsicherheit der Erklärung keine geringe Bedeutung für die Bestimmung der Grïndungszeit des baetischen Kaisercultus hat.

Diese Inschrift ist nur durch die folgende Copie von Morales iiberliefert, C. II 3271 :

FISCI · ET · CVRATORI - DIVI · TI · II - IN BAE

TICA - PRAE - GALLECIAE - PREF - FISCI

GERMANIAE - CAESARVII - IMP . TRIBV

NO LEG . VIII . FLAMINI AVGUS'IALI

IN . BAETICA PRIMO . . . . . . . . . . .

Ohne auf eine nähere Prüfung dieser Copie einzugehen, wollen wir hier nur bemerken, daß in Z. 1 augenscheinlich $T i[t] i$ mit Hübner zu lesen ist ${ }^{{ }^{5}}$ ). Ferner möchten wir empfehlen in Z. 3 GERMANIAR $(u m)$ zu lesen ${ }^{153}$ ), wodurch eine von Hübner hervorgehobene Schwierigkeit ${ }^{154}$ ) beseitigt wird.

Eigentlich aber haben wir die Schlußworte der Inschrift: flamini Augustali in Baetica primo, zu besprechen. Daß das Wort primo mit den vorhergehenden zu verbinden ist, ist zwar höchst wahrscheinlich, aber doch nicht sicher ${ }^{155}$ ); man muß also immerhin mit der Möglichkeit rechnen, daß dieses Wort zu denjenigen gehört, welche auf dasselbe unmittelbar folgten (etwa pilo oder dgl.). Nehmen wir aber dennoch an, daß dasselbe zu dem Vorhergehenden gehört, so müssen wir in den Worten flamini Augustali in Baetica primo unzweifelhaft die Bezeichnung eines einzigen Amtes erblicken ${ }^{156}$ ).

Es fragt sich nun, wie der Titel famen Augustalis in Baetica

152) Es ist als Curiosität zu erwähnen, daß E. Ciccotti ( $I$ sacerdozi municipali e provinciali della Spagna in der Rivista di filol. e d'istruz. class. XIX, 1891, p. 27) im überlieferten TI offenbar Ti(berii) erblickt; auch trägt er kein Bedenken, den am Ende der fraglichen Inschrift erwähnten flamen Augustalis in Baetica primus als einen castulonensisclien Municipalflamen anzusehen (l. 1. p. 5,$3 ; 26$ sq.). Doch liegt es am Tage, daß es sich hier um einen provinzialen Priester handelt.

${ }^{153}$ ) Wohl weniger wahrscheinlich wäre die Emendation: Germaniae $\operatorname{INF}$ (erioris) Caesarum, tribuno u. s. w.

${ }^{154}$ ) Fiscum Germaniue, sagt er im Corpus, dici potuisse item non videtur omnino negandum esse, . . . . sed deesse non potuit Germaniae superioris inferiorisve distinctio.

${ }^{165}$ ) Die von Ciccotti 1. 1. p. 26 sq. beigebrachten Argumente, mit denen er die Nothwendigkeit der obigen Verbindung zu beweisen suchte, sind wohl nicht überzeugend.

${ }^{166}$ ) Wir haben schon oben (Anm. 28) die von Guiraud zweifelnd vorgeschlagene Lesung flamini Augustali, in Baetica primo abgewiesen. Keine größere Zustimmung würde wohl auch die Lesung flamini, Angustali in Baetica primo verdienen, die übrigens von Niemandem empfohlen worden ist.

Broughnt to you by | Université Paris Ouest Nanterre La Défense 
primus und speciell die Bezeichnung primus in diesem Zusammenhange zu deuten ist. Das Einfachste und Natülichste ist es ja anzunelmen, daß dieser Titel sich auf den ersten baetischen Provinzialpriester überhaupt bezieht. Wohl weniger wahrscheinlich, wenn auch an sich möglich, wäre eine andere Deutung, nach welcher der Besitzer des fraglichen Titels der Erste unter den Pricstern von Baetica gewesen sei, dem der Alleincultus eines Kaisers aufgetragen würde, während seine Vorgäinger einen zusammengesetzten Cultus -- etwa den der Göttin Roma und des Augustus oder denjenigen Divorum et Augustorum - verrichtet hätten. Es mag endlich Einer glauben, daß unser Provinzialflamen deshalb als primus bezeichnet werde, weil dessen Vorginger etwa pontifices geheißen haben ${ }^{157}$ ), doch geniigt es zur Widerlegung dieser Vermuthung ${ }^{158}$ ) auf die hauptst:idtische Herkunft des provinzialen Cultus zu verweisen, welche einen derartigen Gebrauch des Titels pontifex ausschlieBt ${ }^{159}$ ).

\section{XIV.}

Halten wir also an der ersten Deutung des Titels flamen Augustalis in Baetica primus fest, so entsteht die Frage, welcher Epoche die Bekleidung des baetischen Provinzialflaminats durch den ungenannten Priester unserer Inschrift und folglich auch die Gründung des baetischen Kaisercultus ungefähr zuzuschreiben ist.

Da nun der cursus honorum unseres Priesters in der Inschrift offenbar in der herabsteigenden Ordnung angegeben ist ${ }^{160}$ ), an der ersten Stelle aber die demselben von Titus aufgetragene Curatel der Provinz Bactica genannt wird, so liegt es am Tage, daß sowohl die Regierung der in Z. 3 erwähnten Caesares imperatores, als die Einrichtung des baetischen Provinzialcultus in die Zeit vor der Thronbesteigung Domitians fallen. Die Bekleidung des Provinzialpriesterthums ist wohl um wenige Jahre der ger-

157) $\mathrm{Zu}$ vergleichen wäre dazu der Umstand, daß gerade in Baetica die Kaiserpriester mehrerer - doch jedenfalls nicht aller (vgl. Philol. 1892 S. 699 Anm. 17) - Gemeinden pontifices und nicht, wie sonst überall, flamines ließen, worüber Näheres $\mathrm{s}$. in meiner Dissert. 8810 u. 11 S. $9 \mathrm{ff}$.

188) Sie ist übrigens, wie auch die vorhergehende Erklärung des fraglichen Titels, von Niemandem ausgesprochen worden.

${ }^{168}$ ) Es unterliegt keinem $Z$ weifel, daß der von Jung (Roemer und Romanen in den Donaulaendern ${ }^{2}$, Innsbruck 1887 S. 145 Anm. 4) als "völlig räthselhaft" bezeichnete pontif(ex) sacr(orum) Raet(icorum) C. V 3927 , den Guiraud (Les assembl. prov. S. 54 Anm. 6) für einen Provinzialpriester Raetiens hält, in der Wirklichkeit ein arusnatischer bzw. veronensischer Municipalpriester gewesen ist, über dessen Competenz meine Ausführung im Philol. $1892 \mathrm{~S} .693 \mathrm{f}$, zu vergleichen ist.

180) Vgl. Hirschfeld Untersuch. auf d. Gebiete der röm. Verwaltungsgesch. I S. 247.

Brought to you by | Université Paris Ouest Nanterre La Défense 
manischen Fiscuspraefectur des baetischen Flamens vorausgegangen; daher muß auch die Einfihrung des Provinzialcultus in Baetica etwa um die Zeit der obigen Caesares imperatores stattgefunden haben. Aber es lïßt sich leider nicht mit Sicherheit bestimmen, welche Kaiser unter diesen Caesares imperatores zu verstehen sind. Am nächsten liegt es, sie mit Riicksicht auf ihren Titel (Caesares imperatores, nicht Augusti) für zusammenregierende Cacsaren zu halten, in welchem Falle wir zunächst an Vespasian und Titus denken müssen ${ }^{161}$ ). Sind dagegen hier mehrere nacheinander regierende Herrscher gemeint, so sind es ohne Zweifel Vespasian (bzw. 'Titus) und dessen nächste Vorgänger. Da nun weder die der vespasianischen Regierung unmittelbar vorangehende Zeit wegen ilhrer Unruhen, noch Nero's Herrschaft ${ }^{162}$ ) für die innere Organisierung der Provinzen günstig waren, so empfiehlt es sich am meisten, eben den Vespasianus für den Urheber des baetischen Provinzialcultus zu halten, zumal da derselbe Kaiser dieses Institut auch in Africa eingefülurt hat ${ }^{163}$ ).

Es sei schließlich eine tuccitanische Inschrift des L. Lucretius Fulvianus flamen col(oniarum) immunium provinciae Baetic(ae), pontifex perpetuns domus Aug(ustae) erwähnt (C. II 1663), die ebenfalls von der verlältnißmäßßig späten Einführung des provinzialen Kaisercultus in Baetica freilich indirect zu zengen scheint. Nach der richtigen Bemerkung von Hirschfeld ${ }^{\mathbf{1 6 4}}$ ) mag der flamen coloniarum immunium provinciae Baeticae dem flamen provinciae in Baetica zeitlich vorausgegangen sein. Es liegt demnach die Vermuthung nahe, daß dieser gemeinsame Kaisercultus der bactischen coloniae immunes nichts anderes als eine Art Surrogat des provinzialen Cultus war. Dieser Erklïrung widerspricht natürlich nicht im Mindesten das Fortbestehen des Flaminats der obigen Colonien

$\left.{ }^{161}\right) \mathrm{Zu}$ vergleichen ist die bei Martialis $3,95,5$ u. 9, 97, 5 vorkommende Bezeichnung Caesar uterque, die sich nach Mommsen's Deutung (Staatsrecht II ${ }^{3}$ S. 888 Anm. 4) möglicher Weise ebenfalls auf Vespasian und Titus bezieht.

162) Eine noch frühere Epoche, wie etwa die des Claudius oder des Gaius, in Betracht zu ziehn, ist ja mit Rücksicht auf die Amtscarriere unseres Priesters nicht rathsam.

${ }^{163)}$ Es mag außerdem beachtet werden die Stelle Plin. N. $I$. 3, 30 universae Hispaniae Vespasianus imperator. Augustus iactatum procellis rei publicae Latium tribuit. L's sei noch beiläufig bemerkt, daß es aus der igabrensischen Inschrift C. II 1614, die einen trib(unus) mil(itum) leg. VI Victricis Piae Felicis, flamen provinc. Baeticae erwähnt, auf den vorvespasianischen Ursprung des baetischen Provinzialcultus keineswegs zu schließen ist, vgl. Hübner's Anm. zu dieser Inschrift.

184) Sitzungsber. S. 840 Anm. 35 a. Woh! au; Torsehen schreibt er die fragliche Inschrift der frühon Kăiscrzeit $z u$ : demn Mühner, der das Original gesehen hat, bezengrt es ausdrücklich, daß dicse Insc? rift der Buchstabenform nach dem Zeitalter der Antonine angehört.

Brought to you by Université Paris Ouest Nanterre La Défense 
noch im Zeitalter der Antonine, d. h. selbst nachdom das eigentliche Provinzialpriesterthum in Baetica schon längst eingerichtet worden war $^{165}$ ).

\section{$\mathrm{XV}$.}

Fassen wir endlich den geographischen Complex der gallischen Provinzen ins Ange, so ist zunächst der große Unterschied zwischen dem narbonensischen Gallien und den sogenannten 'Tres Galliae in Bezug auf die Höhe ihres Culturniveaus hervorzuheben. Eine durchgreifende Romanisierung der Gallia Narbonensis ist von Plinius dem Aelteren ausdrïcklich bezeugt $(N . H .3,31)$ : Narbonensis provincia, sagt er, agrorum cultu, virorum morumque dignatione, amplitudine opum nulli provinciarum postferenda breviterque Italia rerius quam provincia. Wie man sieht, stimmt dieses plinianische Urtheil mit dem oben (Cap. XII) angeführten Berichte von Strabo iiber die Culturzustände von Baetica fast wörtlich iiberein, und man kann sicherlich annehmen, daß das narbonensische Gallien in Bezug auf die Culturentwicklung zu den Tres Galliae etwa in demselben VerhältniB stand, wie Baetica zu den übrigen Provinzen der iberischen Halbinsel ${ }^{166}$ ).

105) Noch wollen wir die dacischen Titel flamen coloniarum und Augustalis coloniarum (?), die Mommsen C. III p. 229 mit dem soeben erwähnten baetischen flamen coloniarum immunium vergleicht, kurz besprechen. Der erstere kommt in einer von Mommsen abgeschriebenen Inschrift aus Sarmizegetusa vor, C. III 1482: T. [ Va]r [en]io Proto... qq. col(oniae) Varen(ius) Pudens fl(amen) coloniarum, eq. p., praef. coh(ortis), patri; der zweite in der folgenden nur handschriftlich überlieferten Iuschrift aus Apulum C. III 1069: T. Cl(audius) Anicetus Aug(ustalis) coloniar(um) templum . . . a solo restituit. Mit Rücksicht auf analogen Sprachgebrauch anderer Inschriften, wie C. III suppl. 6818 (s. oben Aum. 94) curatori colonior(um) et municipior(um), ib. V 3254 curator rerum publicarum, ib. X 1770 uxor patroni civitatium; vgl. noch ib. VI 3842 cur(atori) [. . . . . rerum publ]icarum, wo nach cur(atori) etwa compluv(ium) oder et patr(ono) zu ergänzen ist; ferner ib. IX 1006 cur(ator) civitatium conplurium, Wilm. 2104 patrono municipii et complurium civitatum; C. VIII 865 cur(atori) multar(um) civit(atum), möchten wir auch das in den beiden fraglichen Titeln gebrauchte coloniarum als einen kürzeren Ausdruck für etwa complurium coloniarum betrachten. Uebrigens ist die Lesung COLONIAR in der apulensischen Inschrift (C. III 1069) nicht ganz sicher, weshalb man auch an andere Lesungen denken kann, wie COLONIAE (so Lazius ed.) oder CO. LON ·AP $(u l i)$, was Mommsen, oder COLON(iae) SAR(mizegetusae) bzw. ZAR(mizegetusae), was Ilirschfeld Sitzungsber. S. 841 Anm. 35 a vorschlägt; zu der letzteren Enendation vgl. C. III 1440 Quadrib(is) Cl(audius) Anic[e]tus Aug(ustalis) c(olomiae) Sarmiz(egetusae) metrop(olis) ex voto.

$\left.{ }^{166}\right)$ Es lohnt sich dabei dem Leser in Erinnerung zu bringen, daß diese übrigen sowohl spanischen als gallischen Provinzen unter der Brought to you by | Université Paris Ouest Nanterre La Défense 
Ist aber dem so, so ist von vorne herein zu erwarten, daß die Griindung des Kaisercultus in der narbonensischen Provinz im Vergleich mit der Eimrichtung desselben in ilhren gallischen Nachbarländern relativ ebenso spät stattfinden mußte, wie es in Baetica im Vergleich mit den iibrigen spanischen Provinzen der Fall war.

Inwieweit nun diese Erwartung sich durch positive 'Thatsachen und sonstige äußere Gründe bestätigt, das weiß der ILeser schon aus dem bisher Gesagten. Dem wir glauben bereits oben zur Geniige dargethan zu liaben, daß der Kaisercultus der Tres Galliae schon im Jahre 12 v. Chr., der des narboncnsischen Galliens aber friilhestens von Vespasian gestiftet worden ist ${ }^{167}$ ).

Der Gewinn aber des Nachweises, daß die Beobachtung des ganzen Entwicklungsprocesses des uns beschäftigenden Instituts nothwendig dazu führt, die Einrichtung desselben in Gallia Narbonensis von vorne herein in eine verlältnißmäßig späte Zeit zu versetzen, ist der, daß jene (in Cap. VIII formulierte) principielle Prïsumption, die wo nicht die einzige, so doch eine der Hauptstiitzen der gegnerischen Meinung ist, sich als irrig erwiesen hat und vielmelır einem zu Gunsten unserer Ansicht sprechenden inneren Wahrscheinlichkeitsgrund Platz machen muß.

\section{XVI.}

Im Obigen lıaben wir die sïmmtlichen Gründe entwickelt, die unscre Altersbestimmung des narbonensischen Provinzialgesetzes bzw. Provinzialcultus eigentlich bedingen. Wohl mag daher eine weitere Bekräftigung unserer Ansicht entbehrlich sein; wir wollen es doch nicht unterlassen, auf einige für dieselbe zeugende Umstände linzuweisen, welchen wenigstens in ihrer Gesammtheit eine gewisse Bedeutung bei Lösung der uns beschäftigenden Frage nicht abzusprechen ist.

Zunächst können wir ganz sicher behaupten, daß die Sprache

Verwaltung der kaiserlichen Legaten standen, während Baetica und Gallia Narbonensis in den Bereich der Senatsherrschaft gehörten.

167) Mit Rücksicht auf die Geschichte der Cultuseinführung in den Complexen der spanischen und gallischen Provinzen möchten wir glauben, daß auch der africanische Provinzencomplex keine Ausnahme aus der allgemeinen Regel bildete. Da nun einerseits zwischen der ruhigen, schon längst romanisierten Provinz Africa propria und den wilden und aufrührerischen Numidien und Mauretanien derselbe Gegensatz der Cultur bestand wie zwischen Baetica und den übrigen spanischen oder zwischen Gallia Narbonensis und den übrigen gallischen Provinzen, andererseits der Provinzialcultus in Africa ebenso spät wie in Baetica und in Gallia Narbonensis eingefüht worden ist, so ist es wohl denkbar, daß auch Numidien und Mauretanien den Kaisercultus schon vor Vespasianus also früher als die Provinz Africa erhielten 
der fraglichen Urkunde im Allgemeinen eine weit größere Aelnlichkcit mit der der Gesetze von Salpensa und Malaca aufweist als mit derjenigen der augusteischen Gesetze ${ }^{168}$ ).

Vom orthographischen Standpunkte aber ist hervorzuheben, daß in Z. 28 des narbonensischen Gesetzes die Form praeerit sich findet, welche Schreibwcise den Originalurkunden der augusteischen Zeit fremd ist und zuerst in der Epoche der Flavier - in den Gesetzestafeln von Malaca und Salpensa - vorkommt ${ }^{169}$ ), während dic älteren Schriftdenkmäler ausschließlich die contrahierten Formen praerit, praeruni u. dgl. aufweisen. Mit vollem Recht hat also Hirschfeld in C. XII p. 864* zur obigen Zeile des Gesetzes angemerkt: 'praeerit duplici $e$ scriptum in eius aetatis lege inveniri notabile est' ${ }^{\prime}{ }^{170}$ ).

Es möge endlich der Umstand Erwähnung finden, daß die :ilteste von den mehr oder weniger sicher datierbaren Inschriften, welche sich auf die Provinzialpriester von Gallia Narbonensis beziehen, der Regierungszeit des Traianus bzw. des Titus angehört: wir meinen die oben in Cap. VII besprochene Inschrift des M.

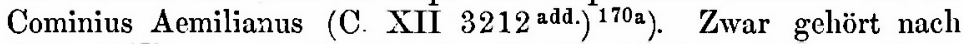
Guiraud ${ }^{171}$ ) etwa in die Zeit des Claudius die folgende nemausische Inschrift $\left.{ }^{172}\right)$ : Q. Solonio Q. f. Vo[l.] Severino ex $V$ decuriis, equo publico, luperco, IIIIvir(o) ab aerar(io), pontifici, flamini provinciae Narbonensis, doch scheint diese Altersbestimmung auf einem Mißverständniß zu beruhen ${ }^{173}$ ). Der sachkundige Leser braucht wohl

${ }^{168}$ ) Vgl. die bei Bruns Fontes iur. Rom. antiq. ${ }^{6}$ I p. 114 sq. 238 sq. angeführten Urkunden.

$\left.{ }^{169}\right)$ Vgl. Corssen Ueb. Ausspr. etc. II ${ }^{2}$ S. 713 f.

$\left.{ }^{170}\right)$ Uebrigens ist die obige Thatsache von Gewicht eigentlich nur für die Altersbestimmung der narbonensischen Bronzetafel, nicht aber für diejenige des Gesetzes selbst: wir können nämlich mit Rücksicht auf das Vorkommen der Schreibung praeerit wohl nur das als sicher behaupten, daB diese Bronzetafel frühestens zur Zeit der flavischen Kiaiser verfertigt worden ist, womit auch die Form der Buchstaben vollkommen übereinstimmt: 'Titterae formae sunt minutae, sagt Hirschfeld C. XII p. 864, haud elegantes, sed omnino bonae aetatis imperatoriae'. Es läßt sich freilich nicht mit Sicherheit bestimmen, ob wir in der erhaltenen Urkunde eben das Original oder eine spätere Copie des Gesetzes besitzen. Die Vertheidiger der üblichen Altersbestimmung des Gesetzes müssen natürlich darauf bestehen, daß die Bronzetafel vielmehr späteren Ursprungs sei ; für uns dagegen hat die Frage nach dem Alter der Tafel selbstverständlich keine besondere Wichtigkeit.

${ }_{170} 0_{\text {a }}$ Betreffs der Inschrift C. XII 392 (oben Anm. 42) vgl. Cichorius bei Pauly-Wissowa, Real-Encycl. I (Stuttg. 1893) Sp. 1250.

171) Les assembl. prov. S. 48.

175) C. XII $3184=$ Herzog Gall. Narbon. hist., append. epigr. n. 106.

${ }^{173}$ ) Es scheint nämlich Guiraud die auf den Severinus bezüglichen Worte Herzog's: 'cum IIII vir ab aerario fuerit, non ultra medium primum p. Ch, saeculum recedit' (Gall. Narb. hist, p, 255) mißverstanden 
nicht meinerseits daran erinnert zu werden, daß die Inschrift des Severinus zu denen gehört, welche nur die Bestimmung des terminus a quo zulassen. Noch irriger ist Mispoulet's Bchauptung, mit welcher derselbe Alibrandi's Einwendungen gegen die Versetzung des narbonensischen Gesetzes in die vespasianische bzw. domitianische Zcit zu bekriftigen suchte. 'Ajoutons, sagt er, auf 'Guirand's Widerlegung der Allmer'schen IIypothese iiber den flamen primus' Bezug nehmend ${ }^{174}$ ), qu'il est bien difficile de retarder jusqu'd Vespasien l'organisation du concilium de la Narbomnaise attendu qu'il existe dejà un flamine de la Narbonnaise sous Tibere'. Dagegen verweisen wir auf die oben in Cap. II enthaltene Besprechung der athenischen Inschrift C. I. Att. III 623, da Mispoulet gerade aus der Letzteren auf das Bestehen des narbonensischen Provinzialflaminats schon unter Tiberius zu schließen scheint ${ }^{175}$ ). Es lohnt sich endlich in diesem Zusammenhang zu bemerken, $\mathrm{da} \beta$ in der von Hirschfeld abgeschriebenen Inschrift aus Vasio, C. XII 1361: .... ellicae flaminic[ae] divae Aug(ustae) PROP ... . 176), die der Schrift nach der friiheren Kaiserzeit angehört ${ }^{177}$ ), offenbar eine municipale flaminica erwälint wird und keine Provinzialpriesterin von Gallia Narbonensis, wie man es früher auf Grund der falschen Lesung von Millin: PROV, glaubte, indem man a. E. prov(inciae) [Narbonensis] ergiinzte ${ }^{178}$ ).

\section{XVII}

Schließlich wollen wir die Frage erörtern, welcher von den drei Kaisern, deren Namen in Z. 13 bzw. 27 des narbonensischen Gesetzes gestanden haben können (Vespasianus, Domitianus, Nerva), als der Begründer des narbonensischen Provinzialcultus am wallrscheinlichsten $\mathrm{zu}$ betrachten ist ${ }^{179}$ ).

zu haben, da er dieselben so wiedergiebt: 'le personnage étant qualifie TIII vir ab aerario vivait au milieu du 1er siecle' (Les assembl. prorinc. S. 48 Anm. 3).

174) Bulletin critique 1890 S. 11.

175) Vgl. oben Anm. 23.

176) Man muß hier etwa prop [ter merita] oder pro $p$ [ietate] lesen, wie es Hirschfeld richtig bemerkt hat; vgl. auch Herzog zu dessen append. epigr. n. 430.

177) 'Litteris optimis primi saeculi incipientis' nach Hirschfeld's Urtheil. Die Erwähnung der diva Augusta zeigt, daß die Inschrift nicht vor Claudius' Regierung abgefaßt sein kann.

${ }^{178}$ ) So z. B. Henzen 6003 , den u. A. Guiraud Comptes rendus de $l$ Acad. des sciences mor. et polit. N. S. XXX p. 267 n. 3 citiert.

$\left.{ }^{179}\right)$ Hier müssen wir den Leser daran erinnern, daß, wenn unsere Ergänzung von Z. 6 der nemausischen Inschrift C. XII $\$ 212^{\text {ald }}$. (vgl. oben Cap. VII) richtig ist, dieselbe die obige Frage in dem Sinne defi- 
Wir haben oben gezeigt, daß in Z. 13 die Ergänzung der rechten Lücke, deren Länge 17 bis $18 \mathrm{Cm}$. beträgt, bei der Einschaltung des Namens Vespasianus einen Raum von etwa 17,7 bis $18 \mathrm{Cm}$., bei der Lesung Domitianus bzw. Nerva einen Raum von ca. 17,4 bis $17,7 \mathrm{Cm}$. bzw. 15,4 bis $15,7 \mathrm{Cm}$. einnimmt ${ }^{180}$ ).

Was nun die letztere Lesung anbetrifft, so ist zwar der für dieselbe nach der normalen Bercchnung erforderliche Raum selbst fïr die minimale Lünge der Lücke zu klein, doch ist sie nicht deswegen ohne Weiteres zu verwerfen: denn man kann mit Wahrscheinlichkcit eine größere Ausdehnung der betreffenden Zwischenräume oder auch der einzelnen Buchstaben voraussetzen, wodurch die Ergänzung der fraglichen Lücke gerade die Länge von 17 bzw. $18 \mathrm{Cm}$. erreichen kann.

Es spricht jedoch gegen die Einschaltung des Namens Nerva an den betreffenden Stellen des Gesetzes der Umstand, daß der kaiserliche Titel in Z. 27 mit den Worten imperator Caesar beginnt. Man muß nämlich das beachten, daß Nerva's Titel in der officiellen Sprache unzweifelhaft weit häufiger imperator Nerva Caesar Augustus als imp. Caesar Nerva Augustus gelautet hat: wenigstens findet sich nur die erstere Form in dem (einzigen uns erhaltenen) Militärdiplom Nerva's ${ }^{181}$ ), auf allen Münzen desselben Kaisers ${ }^{18 z}$ ) und in allen hauptstädtischen demselben gewidmeten Inschriften ${ }^{183}$ ); sie kommt fermer in weit überwiegender Zahl auch in sonstigen Inschriften vor, während man der anderen Wortstellung (imp. Caesar Nerva Aug.) nur sehr selten begegnet ${ }^{184}$ ). Dagegen fängt Domitians Titel in der officiellen Sprache stets ${ }^{185}$ ), derjenige des Vespasianus aber beinahe stets ${ }^{186}$ ) mit den Worten imperator Caesar an. Daher halten wir mit Rücksicht auf Z. 27 die Ergänzung des Namens von Vespasianus bzw. von Domitianus in den betreffenden Zeilen des Gesetzes für viel wahrscheinlicher als die des Namens von Nerva.

Haben wir also die Wahl nur zwischen dem ersten und dem letzten Kaiser des flavischen Hauses zu treffen, so sehen

nitiv entscheidet, daB die Ehre der Einrichtung des provinzialen Kaisercultus im narbonensischen Gallien dem Vespasianus zuzuerkennen ist.

180) Vgl. oben Cap. VI u. VII.

181) C. III p. 861 .

$\left.{ }^{182}\right)$ Cohen Med. imper. II" S. $1 \mathrm{ff}$.

183) C. VI $950-953$.

184) Vgl. z. B. C. III 216. 3006.

185) Vgl. z. B. dessen Militärdiplome, C. III p. 855-860.

188) So finden wir diese Form des Titels von Vespasianus auf den Münzen desselben (Cohen $\mathrm{I}^{2}$ S. $368 \mathrm{ff}$.), auf den Militärdiplomen (C. III p. 850.852 sq.; Eph. epigr. II p. 457) mit einer einzigen Ausnahme (C. III p. 849 : imp. Vespasianus Caesar Augustus), in der sogenannten lex de imperio Vespasiani (C. VI 930 vv. 24. 28. 30), auf den hauptstädtischen Dedicationsdenkmälerm (ib. 931-935, 939) u. s. w. 
Ueber die Einführung des provinzialen Kaisercultus ete. 189

wir, daß die oben angegebenen iußeren Gründe für beide Herrscher gleich $\left.{ }^{18}\right)$, gewisse innere aber vielmehr für Vespasianus sprechen.

Es macht nümlich das Verhalten Domitians zum Kaisereultus überhaupt ${ }^{188}$ ) die Voraussetzung wahrscheinlich, daß er bei Einführung des narbonensischen Provinzialcultus eher sich selbst oder die gens Flavia zum Object desselben gemacht haben würde ${ }^{189}$ ) als den göttlichen Augustus; in welchem Falle aber der narbonensische Provinzialpriester nicht flamen Augustalis, sondern etwa flamen Flavialis hätte heißen muissen. Gerade das Gegentheil ist dem nüchternen Vespasianus zuzumuthen. Auch kann das Zusammentreffen, daß die ersten Provinzialpriester von Baetica und von Gallia Narbonensis denselben 'Titel flamen Augustalis führten, schwerlich zufällig sein; wir müssen wohl diese Thatsache vielmehr daraus erklären, daß der Kaisercultus in diesen beiden Provinzen von einem und demselben Herrscher gegründet worden ist. Nun haben wir aber ermittelt ${ }^{190}$, daß der baetische Cultus jedenfalls vor Domitianus und aller Wahrscheinlichkeit nach unter Vespasianus seinen Anfang genommen hat. So stimmt Alles zu dem Ergebniß zusammen, daß es eben Vespasianus war, der als "der zweite Begründer des Principats" ${ }^{191}$ ) das Werk seines großen Vorgängers Augustus auch darin zu vollenden strebte, daß er den Kaisercultus da, wo der Letztere noch fehlte, - so in den romanisiertesten Provinzen des Westens, in Africa, in Baetica, im narbonensischen Gallien, - einrichtete.

187) Vgl, oben Cap. VII.

188) Vgl. Hirschfeld Sitzungsber. S. 843 nebst Anm. 46 a u. 47.

189) Man beachte die Gründung der Arae Flaviae in den agri decumates (vgl. Bergk Zur Gesch. u. Topogr. d. Rheinl. S. 141 Anm. 3, Marquardt Röm. Staatsverw. I ${ }^{2}$ S. 277 Anm. 2) und das templum gentis Flaviae zu Rom (Suet. Domit. 1. 5. 15. 17; vgl. Martial. 9, 3, 12; $9,34,2)$.

193) Vgl. oben Cap. XIV.

191) H. Schiller Gesch. der rüm. Kaiserzeit I S. 506.

Rom.

MI. Krascheninnikoff. 